\title{
Cold Season Southwest Asia Precipitation Sensitivity to EI Niño-Southern Oscillation Events
}

\author{
ANDREW HOELL \\ NOAA/Earth System Research Laboratory/Physical Sciences Division, Boulder, Colorado \\ MATHEW BARLOW \\ University of Massachusetts Lowell, Lowell, Massachusetts \\ TAIYI XU AND TAO ZHANG \\ Cooperative Institute for Research in the Environmental Sciences, University of Colorado, and \\ NOAA/Earth System Research Laboratory/Physical Sciences Division, Boulder, Colorado
}

(Manuscript received 7 July 2017, in final form 18 February 2018)

\begin{abstract}
The sensitivity of southwest Asia $\left(25^{\circ}-40^{\circ} \mathrm{N}, 40^{\circ}-70^{\circ} \mathrm{E}\right)$ precipitation during the November-April rainy season to four types of El Niño-Southern Oscillation (ENSO) events, eastern Pacific (EP) and central Pacific (CP) El Niño and La Niña, is assessed using an ensemble of atmospheric model simulations forced by 19792015 boundary conditions. Sensitivity is assessed in terms of 1) the spread of precipitation across the ensemble members around the ensemble mean, 2) the probability of precipitation falling into the upper and lower terciles of the historical distribution, and 3) the relationship between the tropical atmosphere and southwest Asia precipitation during ENSO. During CP La Niña, the magnitude of the below-average mean precipitation exceeds the magnitude of the precipitation spread, thereby conditioning the probability of lower-tercile southwest Asia precipitation to greater than $70 \%$. By contrast, EP La Niña does not alter the odds of southwest Asia precipitation terciles, as the magnitude of the near-zero mean precipitation is overwhelmed by the magnitude of the precipitation spread. EP and CP El Niño similarly result in above-average mean precipitation whose magnitude approaches the magnitude of the precipitation spread, thereby conditioning the probability of upper-tercile southwest Asia precipitation to around 50\% region-wide. However, the notable effect of the precipitation spread during El Niño allows for a $20 \%-30 \%$ probability that the regional precipitation falls into the lower tercile. ENSO types simultaneously modify the probability of eastern Indian Ocean precipitation and southwest Asia precipitation, supporting the hypothesis that the tropical eastern Indian Ocean atmosphere serves as the medium by which ENSO forcing is communicated to southwest Asia.
\end{abstract}

\section{Introduction}

The weather and climate of southwest Asia, defined here as the semiarid region bounded by $25^{\circ}-40^{\circ} \mathrm{N}, 40^{\circ}-$ $70^{\circ} \mathrm{E}$ (Fig. 1, red box), is closely related with El NiñoSouthern Oscillation (ENSO) during the region's November-April rainy season. This relationship was established by analyses that focused on the average southwest Asia precipitation and atmospheric circulation across many ENSO events (Figs. 1a,b). It was found in those previous analyses that the El Niño phase of ENSO is on average related with increased southwest

Corresponding author: Andrew Hoell, andrew.hoell@noaa.gov
Asia precipitation (Fig. 1a; e.g., Barlow et al. 2002; Nazemosadat and Ghasemi 2004; Mariotti 2007; Hoell and Funk 2013; Hoell et al. 2017a), while the La Niña phase of ENSO is on average related with decreased southwest Asia precipitation (Fig. 1b; e.g., Barlow et al. 2002; Nazemosadat and Ghasemi 2004; Hoell et al. 2017a). A review of known dynamical influences on the precipitation of the region is provided in Barlow et al. (2016). The current investigation focuses on examining the variations in the ENSO influence on the region, in terms of both the role of internal atmospheric variability and the role of differences in the ENSO pattern itself. We focus here on a large ensemble of atmospheric simulations, both to separate the internal from the 
SST-forced variability, and to provide sufficient realizations of ENSO events to confidently characterize the modeled atmospheric response to different ENSO patterns. The model provides a generally realistic simulation of both the mean and variability of the region, as discussed further in section $2 \mathrm{a}(2)$.

The previous analyses have focused on the average response of southwest Asia precipitation to ENSO, and the range of responses during ENSO events has not yet been fully investigated. Understanding this range is important both to seasonal forecasting for the region and to dynamical interpretation. For seasonal predictions, it is important to have an estimate of the range of outcomes, especially the likelihood that the seasonal precipitation anomaly will have the opposite sign from the average response, as occurred in the region with below-average precipitation during the 2009/10 El Niño (Fig. 1c) and above-average precipitation during the 1985/86 La Niña (Fig. 1d). Dynamically, the strength of the ENSO relationship has been linked to its spatial pattern in terms of a "westward intensified" pattern (Barlow et al. 2002) and the gradient in SST between the western and central tropical Pacific (Hoell and Funk 2013), although this has not yet been systematically investigated. These analyses have shown that the structure of the ENSO pattern is linked to the strength of the tropical precipitation anomalies in the eastern Indian Ocean and western Pacific. The diabatic heating associated with those tropical convective anomalies can, in turn, generate an atmospheric circulation response that extends over southwest Asia, as shown in a linear model with a zonal-mean basic state (Barlow et al. 2002), a twolayer model with a zonally varying basic state (Barlow 2011), and a full GCM (Barlow et al. 2007), as well as in a Rossby wave tracing analysis (Hoell et al. 2013). Here we analyze two aspects of the variations in ENSO influence on the region during November-April: 1) the importance of the SST anomaly pattern in determining the predictable component relative to the unpredictable spread of southwest Asia precipitation and 2) how those same SST anomaly patterns condition the tropical drivers of southwest Asia precipitation and therefore the probabilities of above- and below-average southwest Asia precipitation.

The ENSO cycle explains approximately $30 \%$ of the November-April southwest Asia precipitation variance (Hoell et al. 2017a), and the general dynamics of this relationship have been studied in some detail. Composites of average conditions across many El Niño and La Niña events indicate that tropical convective anomalies over the eastern Indian Ocean and Maritime Continent are linked with mixed baroclinic-barotropic Rossby waves over southwest Asia (Barlow et al. 2002;
Mariotti 2007; Barlow et al. 2007; Hoell and Funk 2013; Hoell et al. 2013, 2014a, 2015a,b). There are two known mechanisms through which the Rossby waves develop over southwest Asia associated with Indo-Pacific tropical convection. The first is through a Gill-Matsuno-type response (Matsuno 1966; Gill 1980), in which Rossby waves develop poleward and westward of tropical convective anomalies over the Indian and Pacific Oceans (e.g., Barlow et al. 2002). The second mechanism is through stationary Rossby waves with northeastward group velocity originating over the tropical Pacific Ocean (Shaman and Tziperman 2005; Niranjan Kumar et al. 2016). The interaction of the Rossby waves with the mean circulation result in anomalous regional precipitation (Hoell et al. 2012, 2013). El Niño (La Niña) events are on average related with anomalous upperlevel low (high) pressure across southern Asia. The anomalous low (high) pressure across southern Asia interacts with the mean mid- and upper-tropospheric wind, resulting in warm (cold) temperature advection, which is balanced by thermodynamically induced ascent (descent). Above (below)-average regional precipitation therefore results from anomalous ascent (descent) and an enhancement (reduction) of the climatological vertically integrated moisture fluxes and convergence (divergence) into southwest Asia (Chakraborty et al. 2006; Hoell et al. 2017b). While the extension of tropical precipitation anomalies from the Maritime Continent into the eastern Indian Ocean appears to be important and linked to the structure of the ENSO pattern (Barlow et al. 2002), it is not yet clear how that relationship relates to separations of ENSO patterns.

The Pacific SST anomaly patterns between individual El Niño and La Niña events are all different (Wyrtki 1975), and these different SST anomaly patterns have been linked with different anomalous precipitation over southwest Asia. A common distinguishing characteristic of El Niño and La Niña events is the east-west location of the largest SST anomaly in the tropical Pacific Ocean (e.g., Johnson 2013; Capotondi et al. 2015). To that end, El Niño and La Niña events are often separated into eastern Pacific (EP) or central Pacific (CP) typologies (e.g., Kao and Yu 2009). CP La Niña, on average, has been linked with exceptional southwest Asia drought during 1980-2012 (Barlow et al. 2002; Hoell and Funk 2013; Hoell et al. 2014a,b, 2015b, 2017b). However, analyses of the links between EP and CP El Niño and La Niña and the probabilities of November-April southwest Asia precipitation outcomes still remain unexplored.

Southwest Asia precipitation is also related with Indian Ocean and Pacific Ocean SSTs on monthly time scales and decadal-and-longer time scales. During 
(a) EI Nino Average

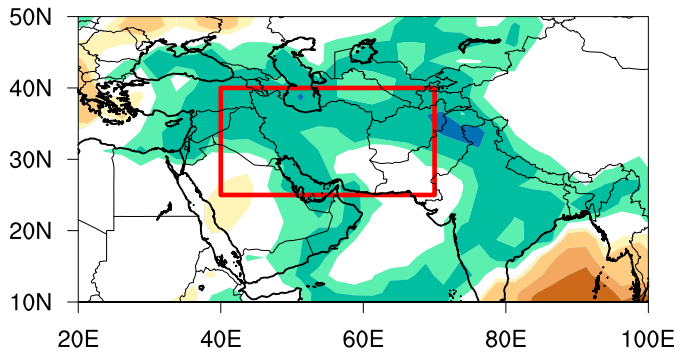

(c) 2009-10 El Nino

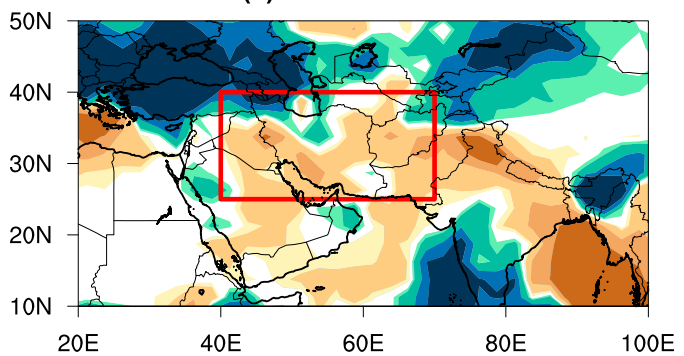

(b) La Nina Average

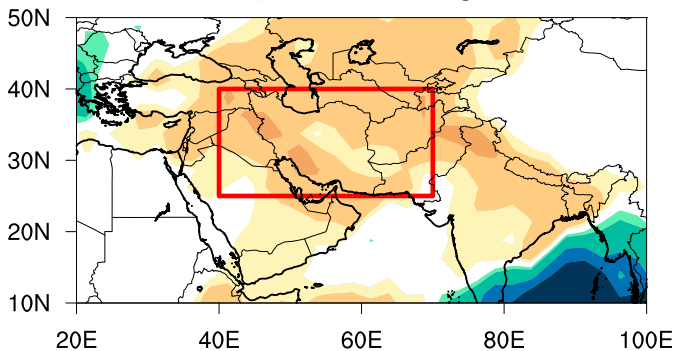

(d) 1985-86 La Nina

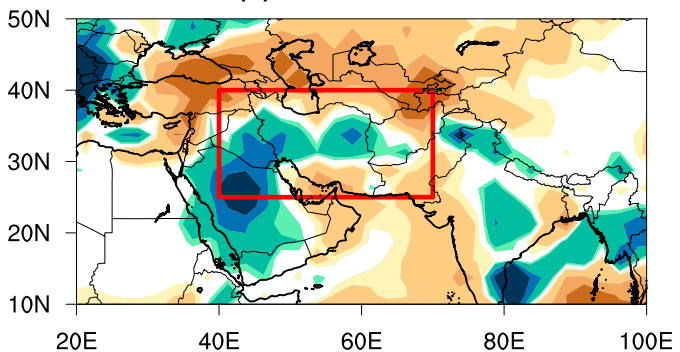

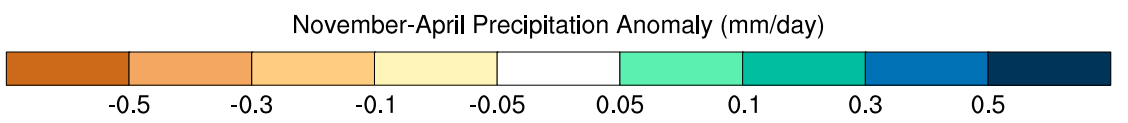

FIG. 1. November-April 1979-2015 avg precipitation anomaly ( $\mathrm{mm} \mathrm{day}^{-1}$ ) during (a) El Niño and (b) La Niña (see Table 1). November-April precipitation anomaly $\left(\mathrm{mm} \mathrm{day}^{-1}\right.$ ) during the (c) 2009/10 El Niño and (d) 1985/86 La Niña. The red rectangles outline southwest Asia.

November and December, Hoell et al. (2015b) and Athar (2015) have identified a relationship between southwest Asia precipitation and Indian Ocean SSTs of a similar pattern as the Indian Ocean dipole (Saji et al. 1999 ) in addition to relationships with ENSO. On longer time scales, Hoell et al. (2015a, 2017a) have identified relationships between decadal variations of tropical Pacific SSTs and multidecadal warming of tropical Indowest Pacific Ocean SSTs with southwest Asia precipitation. These topics merit considerable attention, but are outside the scope of the current analysis, which focuses solely on the relationship between ENSO and the range of possible southwest Asia precipitation outcomes during the entire November-April season.

While SSTs associated with ENSO serve as the primary drivers of southwest Asia precipitation on seasonal time scales (Hoell et al. 2017a), the regional precipitation is also known to be influenced by two primarily atmospheric modes' variability: the Madden-Julian oscillation (MJO) and the North Atlantic Oscillation (NAO). During active $\mathrm{MJO}$ periods, eastward-moving tropical convection centers over the Indian and Pacific Oceans (e.g., Madden and Julian 1972, 1994) excite Rossby waves over southwest Asia that can enhance or suppress the regional precipitation (Barlow et al. 2005; Nazemosadat and Ghaedamini 2010; Hoell et al. 2013). Enhanced tropical eastern Indian Ocean convection associated with the MJO promotes high pressure over southwest Asia and reduces the regional precipitation, while reduced tropical eastern Indian Ocean convection associated with the MJO promotes low pressure over southwest Asia that enhances the regional precipitation. The NAO is related with a downstream modification to the storm tracks, thereby either enhancing or reducing the number of synoptic-scale storms that enter the Middle East and southwest Asia (Cullen and deMenocal 2000; Aizen et al. 2001; Cullen et al. 2002; Krichak et al. 2002; Mann 2002; Syed et al. 2006). Specifically, the negative phase of the NAO increases precipitation and streamflow over the Middle East during mid- and late winter (Cullen et al. 2002).

Those same processes that originate primarily in the atmosphere can contribute to the southwest Asia precipitation spread during an El Niño or La Niña event. One noteworthy example is of a strong MJO event during December 2007/January 2008. This MJO event suppressed Indian Ocean convection for two weeks, which in turn forced an episode of southwest Asia flooding in the midst of the 2007/08 La Niña-related drought (Hoell et al. 2012). Hoell et al. (2012) suggest that had 
it not been for this MJO event, then southwest Asia would have likely been much drier during the critical 2007/08 wintertime rainy season than what actually occurred. It is currently unclear whether the MJO, NAO, or some other primarily atmosphere-only processes were responsible for the unexpected seasonal precipitation outcomes over southwest Asia during the 2009/10 El Niño (Fig. 1c) and 1985/86 La Niña (Fig. 1d) events.

Here we analyze how CP and EP El Niño and La Niña events shape the probability of November-April southwest Asia precipitation anomalies and assess the relative magnitudes of the predictable signal (average precipitation anomaly) and the unpredictable noise (spread of precipitation outcomes around the average) across those same ENSO events. While we quantify the spread of precipitation outcomes during CP and EP El Niño and La Niña events, we do not attribute the causes of the spread to phenomena such as the NAO and MJO. This examination utilizes a 50 -member ensemble of atmospheric model simulations driven by 1979-2015 observed boundary conditions: SSTs, sea ice concentrations, and atmospheric composition. This analysis employs a large ensemble of atmospheric model simulations in order to quantify the spread of southwest Asia precipitation around the average during El Niño and $\mathrm{La}$ Niña events, an exercise that is impossible using only observations because of an inadequately small observed sample size. This analysis will provide additional predictability information, allowing forecasters to create more comprehensive seasonal precipitation predictions during the southwest Asia rainy season, and will also provide an assessment of the sensitivity to ENSO patterns, thereby improving our dynamical understanding of the region.

We were motivated to perform such an assessment of southwest Asia precipitation predictability because the failure or extreme excess of precipitation during the wet season severely impacts the region's water resources and the rain-fed farming upon which the people of the region rely (e.g., Ramankutty et al. 2008; Ryan et al. 2012). Drought over southwest Asia has been shown to foster social and economic instability (Gall 2008) and increase the potential for the loss of life and property (Agrawala et al. 2001). Excess precipitation also brings an array of problems, most notably flooding that destroys property and agriculture. To that end, a better understanding of the magnitude of the predictable signal to the unpredictable spread of precipitation during ENSO empowers forecasters to estimate the probability of wet and dry November-April seasons across the region prior to the start of the rainy season for the purpose of improved early warning.
The rest of the paper is structured as follows. In section 2, tools and methods, we introduce the atmospheric model utilized and its suitability for this analysis, and describe the methods used to analyze predictability, including tercile and signal-to-noise analysis. In section 3 , results, we assess the predictability of southwest Asia precipitation associated with EP and CP El Niño and La Niña events and estimate the probability of wet and dry conditions using the atmospheric model. In section 4, we provide a summary and discussion.

\section{Tools and methods}

a. Tools

\section{1) Observations}

Observed precipitation estimates are drawn from the Global Precipitation Climatology Project (GPCP), version 2.3 (Adler et al. 2003). As discussed in Hoell et al. (2015a, 2017a), southwest Asia is a region in which in situ precipitation sampling is sparse in both time and space. To that end, precipitation estimates over the region that rely solely upon station data will have large coverage gaps. We therefore adopt a precipitation estimate from GPCP because it blends available in situ precipitation observations with remotely sensed estimates of precipitation to provide a consistent and longterm precipitation record.

Estimates of the observed ocean boundary conditions, SSTs, and sea ice are drawn from the merged HadleyNOAA optimum interpolation dataset (Hurrell et al. 2008). The observed SSTs are used to identify CP and EP El Niño and La Niña events while SSTs and sea ice prescribe the ocean boundary conditions in the atmospheric model simulations described in the following. A 1979-2015 mean is used to calculate anomalies of all variables. The observed estimates of precipitation and SSTs are hereafter referred to as "observations."

\section{2) ATMOSPHERIC MODEL SIMULATIONS}

A 50-member ensemble of atmospheric model simulations forced by observed time-varying boundary conditions is used to examine southwest Asia precipitation and atmospheric circulation during November-April 1979-2015 ENSO events. The ensemble of atmospheric model simulations is generated using the GFSv2, which serves as the atmospheric component of the Climate Forecast System, version 2 (Saha et al. 2014). This version of GFSv2 is integrated on a spectral T126 horizontal grid $\left(\sim 0.9^{\circ} \times 0.9^{\circ}\right.$ in. latitude $\times$ longitude $)$ with 64 vertical hybrid sigma-pressure levels. Each GFSv2 ensemble member is forced by identical time-varying 
(a) GPCP Mean and Contribution to Annual

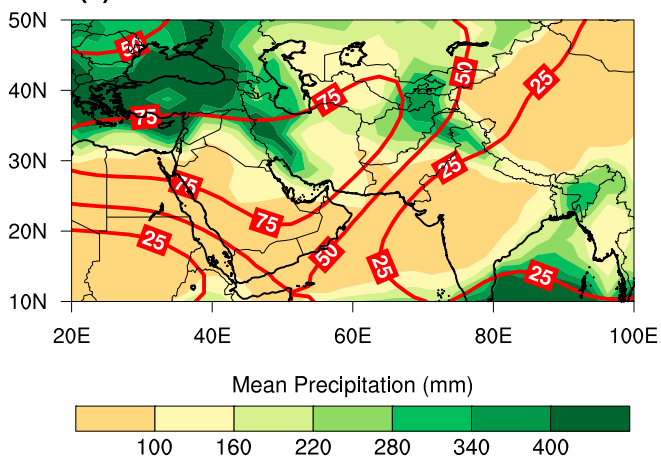

(c) GPCP Coefficient of Variation

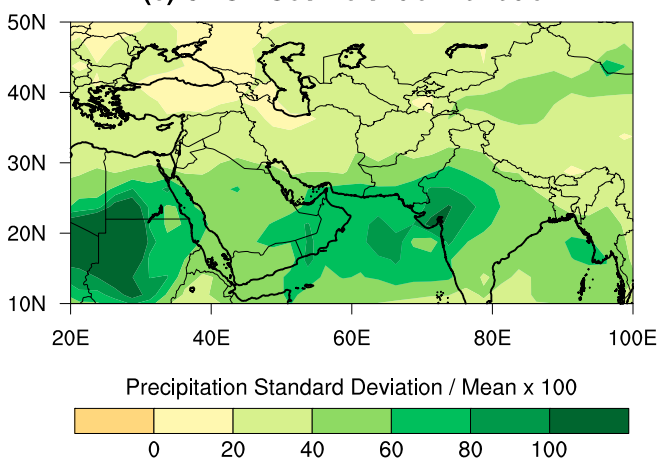

(b) GFSv2 Mean and Contribution to Annual

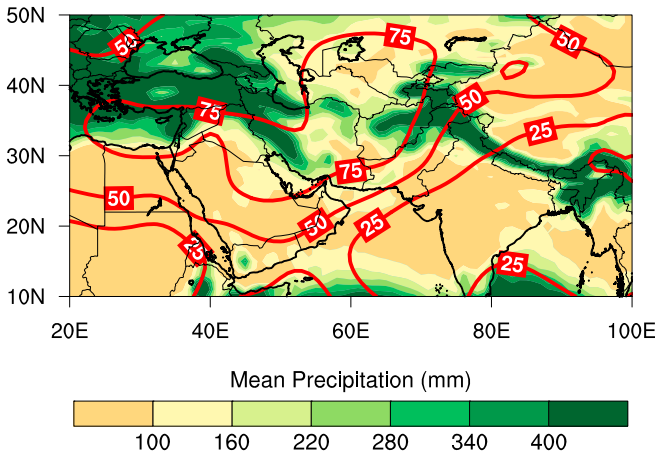

(d) GFSv2 Coefficient of Variation

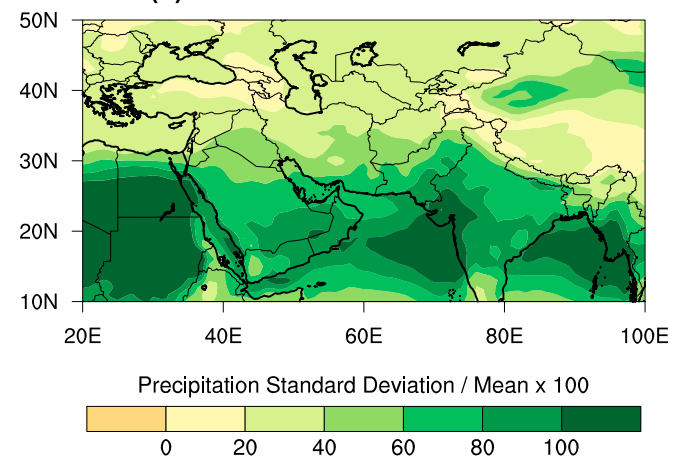

FIG. 2. (top row) November-April mean precipitation (shading; $\mathrm{mm}$ ) and mean contribution to annual precipitation (contour; \%) and (bottom row) precipitation coef of variation in (left column) observations and (right column) the model ensemble members.

SSTs, sea ice, and atmospheric composition, but has different weather owing to their initialization from different atmospheric states. All 50 members of the GFSv2 ensemble were initialized on 1 October 1978, and the initial conditions for each member were each drawn on October 1 of different years of a 200-yr simulation of the GFSv2 model forced by 1981-2010 average boundary conditions. GFSv2 documentation and data can be found at the following URL: https://www.esrl.noaa.gov/psd/ repository/alias/facts. The GFSv2 is hereafter referred to as "the model" and its simulations as "simulations."

The model reproduces key features of the observed November-April 1979-2015 precipitation and is therefore an appropriate tool to examine the spread of southwest Asia precipitation during ENSO events. The model and observations produce similar mean spatial southwest Asia precipitation patterns during the November-April rainy season (Figs. 2a,b; pattern correlation of 0.91 ), and produce similar contributions by November-April precipitation to the annual total (Figs. 2a,b). The greatest precipitation amounts in both the observations and simulations fall along the western slopes of the Zagros Mountains along the border of Iraq and Iran and the Hindu Kush Mountains in Afghanistan. By contrast, the lowest observed and simulated precipitation amounts fall over the lowest elevations of southwest Asia, most notably the Dasht-e Kavir Desert in north-central Iran, the Dasht-e Lut Desert in southeastern Iran, and the Karakum Desert in Turkmenistan. It is noteworthy that the model on average produces higher precipitation amounts than observations throughout most of southwest Asia, especially over the region's highest terrain. The observations and model also produce similar spatial southwest Asia precipitation patterns of variability during the November-April rainy season (Figs. 2c,d; pattern correlation 0.94). Despite the strong similarities between the observed and simulated variability, the model produces greater variability when compared with observations between $25^{\circ}$ and $30^{\circ} \mathrm{N}$.

The areally averaged southwest Asia monthly precipitation distributions resolved by observations and the model during 1979-2015 are also similar (Fig. 3). Similar seasonal cycles are produced by the observations and the model, highlighted by the magnitude of precipitation during the wintertime November-April rainy season and the summertime dry season, and the transition 


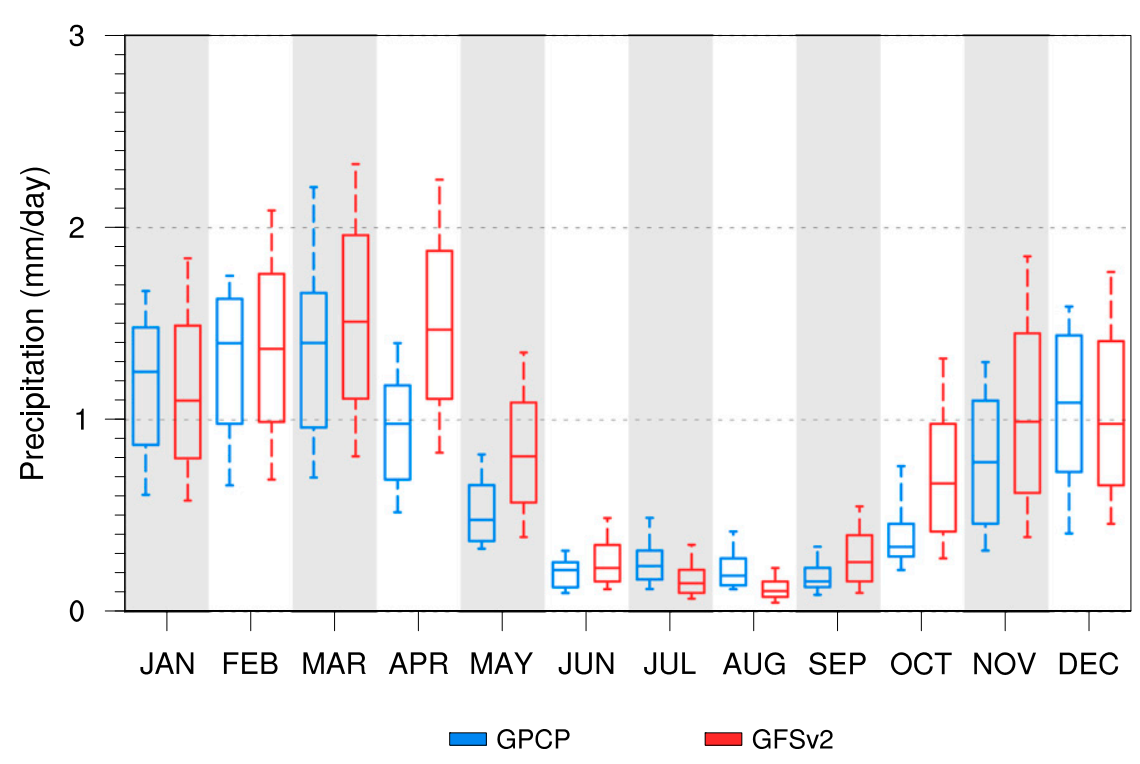

FIG. 3. Box-and-whisker diagram of monthly 1979-2015 areally averaged southwest Asia precipitation resolved by observations (blue) and the model ensemble members (red). Whiskers represent the 10th and 90th percentiles.

between the two. The strong precipitation similarities are especially evident in the observed and simulated monthly medians, interquartile ranges, and extremes. While there are few differences in the monthly precipitation distributions, one notable difference between observations and the simulations is during the month of April, where the model produces about $50 \%$ more rainfall on average when compared with observations.

Observations and the model produce similar characteristics of year-to-year southwest Asia precipitation during 1979-2015 (Fig. 4). Most notably, the spread of simulated precipitation and observed precipitation estimates track closely with one another in time, as the observed precipitation estimates always fall within the spread of the 50-member model ensemble. The simulated ensemble average closely follows the observed precipitation estimates for much of 1979-2015. This close correspondence is somewhat fortuitous. The observed precipitation estimate is a single trace of the climate, which includes the effects of both boundary-forced

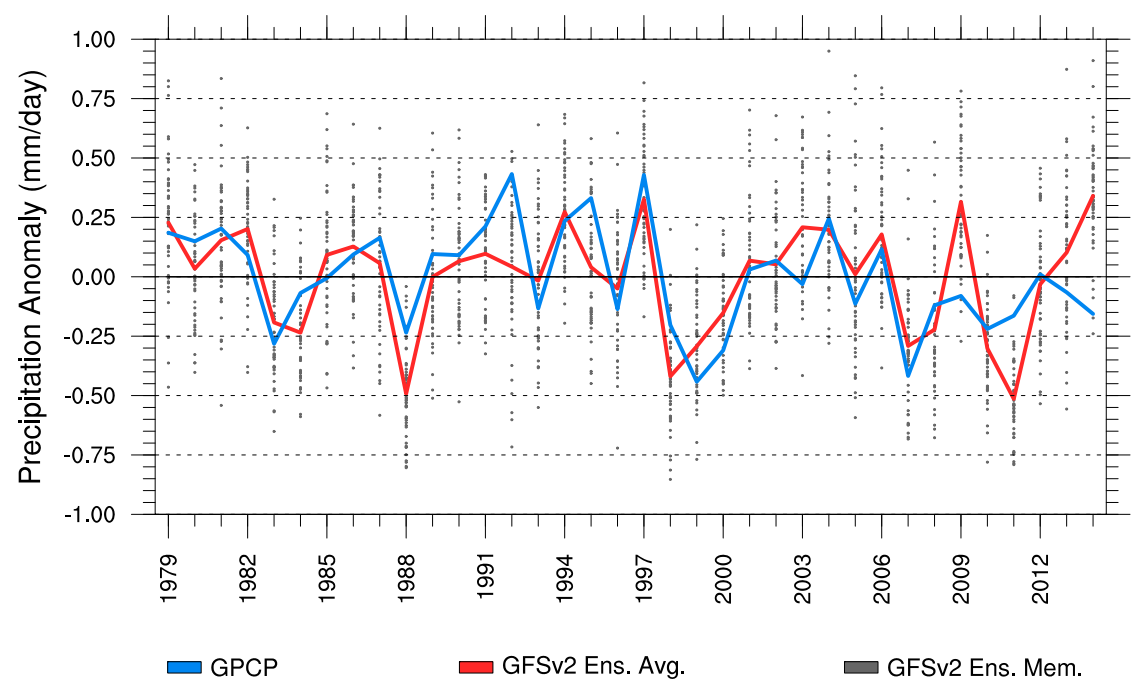

FIG. 4. November-April areally averaged southwest Asia precipitation anomaly $\left(\mathrm{mm} \mathrm{day}^{-1}\right)$ in observations (blue line), the model ensemble members (gray dots), and the model ensemble avg (red line). 
TABLE 1. List of ENSO events.

\begin{tabular}{|c|c|c|c|c|c|}
\hline & ENSO & EP & $\mathrm{CP}$ & EP & $\mathrm{CP}$ \\
\hline & Neutral & $\overline{\text { El Niño }}$ & $\overline{\text { El Niño }}$ & La Niña & La Niña \\
\hline \multirow[t]{13}{*}{ Season } & $1979 / 80$ & $1982 / 83$ & $1987 / 88$ & $1984 / 85$ & $1983 / 84$ \\
\hline & 1980/81 & 1986/87 & $1994 / 95$ & $1985 / 86$ & $1988 / 89$ \\
\hline & $1981 / 82$ & $1991 / 92$ & $2002 / 03$ & $1995 / 96$ & $1998 / 99$ \\
\hline & $1989 / 90$ & $1997 / 98$ & $2006 / 07$ & $2005 / 06$ & $1999 / 00$ \\
\hline & $1990 / 91$ & & $2009 / 10$ & & $2000 / 01$ \\
\hline & $1992 / 93$ & & 2014/15 & & $2007 / 08$ \\
\hline & $1993 / 94$ & & & & $2008 / 09$ \\
\hline & $1996 / 97$ & & & & $2010 / 11$ \\
\hline & $2001 / 02$ & & & & $2011 / 12$ \\
\hline & $2003 / 04$ & & & & \\
\hline & $2004 / 05$ & & & & \\
\hline & $2012 / 13$ & & & & \\
\hline & $2013 / 14$ & & & & \\
\hline
\end{tabular}

information and atmospheric noise, whose analogs are single-simulated ensemble members . By contrast, the simulated ensemble average precipitation isolates the effect of the boundary conditions by muting internal atmospheric noise contained in each ensemble member.

\section{b. Methods}

\section{1) EP AND CP El NiÑO AND LA NiÑA IDENTIFICATION}

ENSO events are separated into four types during November-April 1979-2015 based upon the zonal distribution of SST anomalies in the tropical Pacific Ocean (e.g., Capotondi et al. 2015 and references therein): EP El Niño, CP El Niño, EP La Niña, and CP La Niña. The seasonal occurrences of each ENSO category and ENSO neutral are shown in Table 1.

ENSO events are defined based upon a threshold exceedance of the November-April Niño-3.4 index anomaly, where the Niño-3.4 index is defined as the areally averaged SSTs over the region $5^{\circ} \mathrm{S}-5^{\circ} \mathrm{N}, 170^{\circ}$ $120^{\circ} \mathrm{W}$. El Niño is defined as occurring when the Niño3.4 index anomaly exceeds $0.5^{\circ} \mathrm{C}$, and La Niña is defined as occurring when the Niño-3.4 index anomaly falls below $-0.5^{\circ} \mathrm{C}$.

An ENSO event is defined as EP or CP based upon the zonal distribution of November-April SST anomalies in the tropical Pacific Ocean using the definition of Kug et al. (2009) and Yeh et al. (2009). An EP El Niño (La Niña) is defined as occurring when the Niño-3 index exceeds (falls below) 1 standard deviation and the Niño3 index is greater than (less than) the Niño-4 index. A CP El Niño (La Niña) is defined as occurring when the Niño-4 index exceeds (falls below) 1 standard deviation and the Niño-4 index is greater than (less than) the Niño-3 index. The Niño-3 index is defined as the areally averaged SSTs over the region $5^{\circ} \mathrm{S}-5^{\circ} \mathrm{N}, 150^{\circ}-90^{\circ} \mathrm{W}$, and the Niño-4 index is defined as the areally averaged SSTs over the region $5^{\circ} \mathrm{S}-5^{\circ} \mathrm{N}, 160^{\circ} \mathrm{E}-150^{\circ} \mathrm{W}$.

The average SST anomaly patterns of the four ENSO flavors during November-April 1979-2015 are distinctly different (Fig. 5). EP El Niño is defined by warm equatorial Pacific SST anomalies over the central and eastern Pacific Ocean and cool SST anomalies over the western Pacific in a pattern similar to canonical El Niño first described by Rasmusson and Carpenter (1982) (Fig. 5a). By contrast, CP El Niño is defined by warm equatorial Pacific SST anomalies centered along the date line with near-average SST anomalies over the western and eastern Pacific, as initially described by Larkin and Harrison (2005) and Ashok et al. (2007) (Fig. 5b). EP La Niña is defined by an equatorially confined cool SST anomaly that extends from the date line to the coast of South America, with weak SST anomalies elsewhere (Fig. 5c). EP La Niña most closely resembles the second of nine SST anomaly patterns associated with ENSO identified by Johnson (2013). CP La Niña is also defined by cold SST anomalies that extend from the date line to the coast of South America, with the strongest SST anomalies present near the date line. Also associated with CP La Niña is a warm west Pacific Ocean that flanks the cool SST anomalies poleward.

\section{2) ENSO PRECIPITATION PREDICTABILITY AND EXCEEDANCE PROBABILITIES}

The predictability of November-April southwest Asia precipitation is assessed using the signal-to-noise ratio (e.g., Kumar and Hoerling 2000; Sardeshmukh et al. 2000; Kumar and Chen 2017) of the ensemble of model simulations during EP and CP El Niño and La Niña. For example, during the nine CP La Niña events, the signal-to-noise ratio is the ratio of the absolute value of the average precipitation anomaly (the signal) to the precipitation anomaly standard deviation (the noise) across the 450 simulated November-April seasons. The average precipitation anomaly is the signal, as the noise introduced by each ensemble member is muted through the averaging, thereby highlighting the effect of the boundary conditions such as SSTs on precipitation. The precipitation standard deviation across the ensemble members is the noise, as it identifies the possible precipitation spread as a result of random atmospheric behaviors. Signal-to-noise ratios approaching and exceeding 1.0 demonstrate that the effect of the boundary conditions is important relative to the effect of random atmospheric noise, and therefore the boundary conditions provide predictive information. By contrast, smaller signal-to-noise ratios 
(a) EP EI Nino

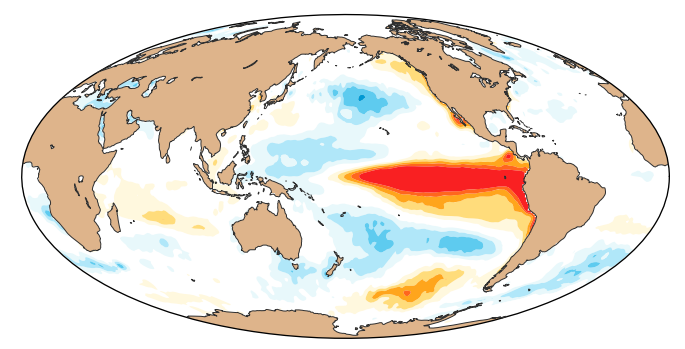

(c) EP La Nina

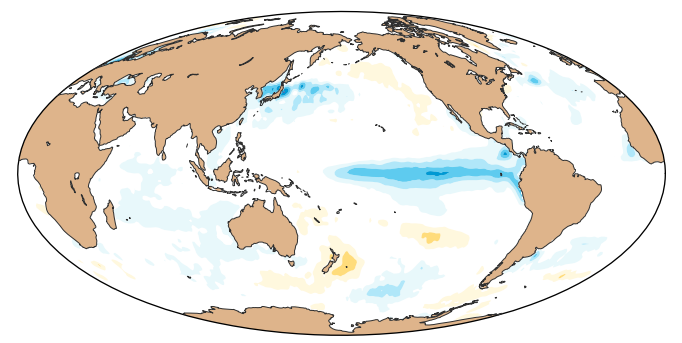

(b) CP El Nino

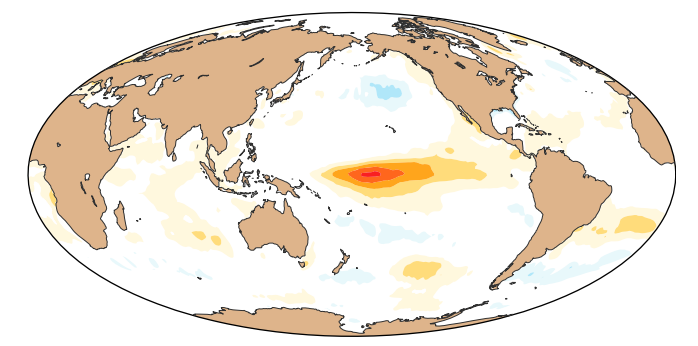

(d) CP La Nina

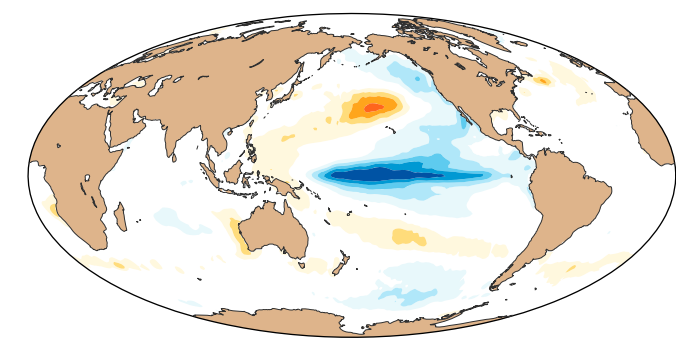

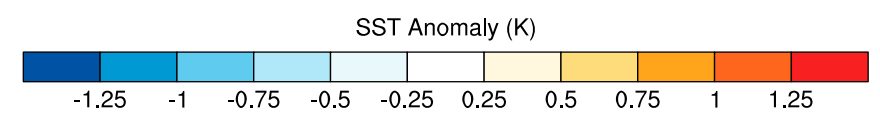

FIG. 5. November-April avg SST anomaly (K) during (left column) EP and (right column) CP (top row) El Niño and (bottom row) La Niña. SST anomalies are significant at $p<0.05$ according to a two-sided $t$ test.

demonstrate that the effects of unpredictable noise overwhelm the effect of the boundary conditions, and therefore the boundary conditions provide little predictive information.

The probability that November-April precipitation anomalies fall below average, near average, or above average during EP and CP El Niño and La Niña is estimated using the ensemble of model simulations. Belowaverage, near-average, and above-average precipitation are commonly defined by the bottom-, middle-, and upper-thirds (terciles) of a precipitation distribution in seasonal precipitation forecasts [see Becker and van den Dool (2016) for a description of tercile forecasts using the North American Multimodel Ensemble]. We adopt a similar approach. Tercile thresholds are identified through a ranking of precipitation across the 50 members of the model ensemble over the 37-yr record for 19792015. At every model grid point, the 33rd and 66th percentiles, corresponding to the lower- and upper-tercile boundaries, are identified. We then identify the proportion of the ensemble members that fall into each tercile of the distribution during each ENSO type. Using CP La Niña as a representative ENSO type, we identify the proportion of the 450 ensemble members that fall into each tercile of the distribution.

\section{Results}

\section{a. La Niña}

\section{1) Precipitation PRedictability}

The widespread signal-to-noise ratios near 1 standard deviation across southwest Asia and the southern half of the Arabian Peninsula in the ensemble of model simulations (Fig. 6a) suggest that CP La Niña offers considerable precipitation predictability during November-April. The precipitation signal is negative region-wide and is particularly strong over those same elevated regions in which the signal-to-noise ratio is largest (Fig. 6b). The magnitude and pattern of the precipitation signal in the ensemble of model simulations (Fig. 6b) are similar to the average observed precipitation anomaly during all La Niña events after 1979 (Fig. 1b) as well as the observed precipitation during CP La Niña events during that same time period (Fig. 3; see also Hoell et al. 2014a,b, 2017b). The precipitation noise during CP La Niña is notable throughout the region, even across locations in which the magnitude of the signal is quite large (Fig. 6c). While the magnitude of the predictable precipitation signal matches and exceeds the magnitude of the 
(a) CP La Nina Signal-to-Noise Ratio

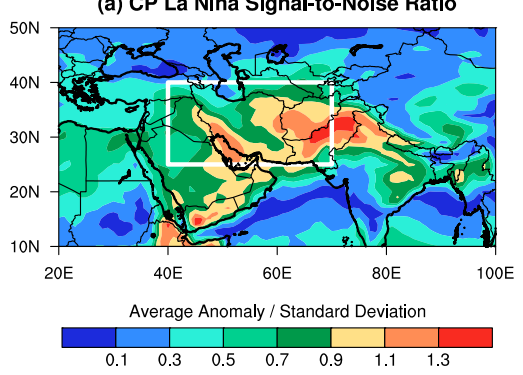

(d) EP La Nina Signal-to-Noise Ratio

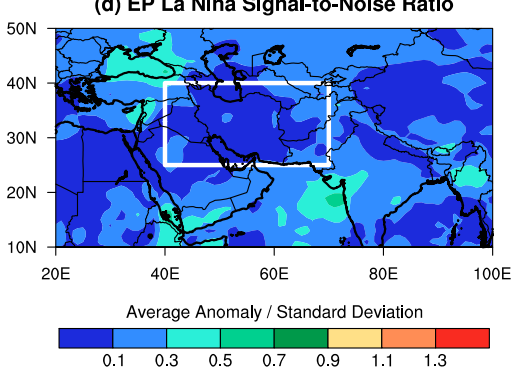

(b) CP La Nina Signal

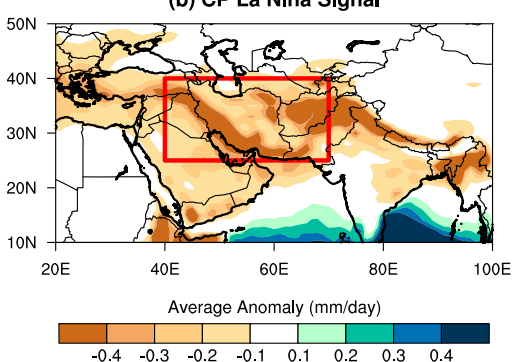

(e) EP La Nina Signal

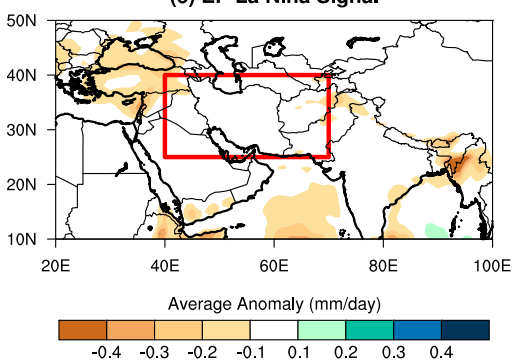

(c) CP La Nina Noise

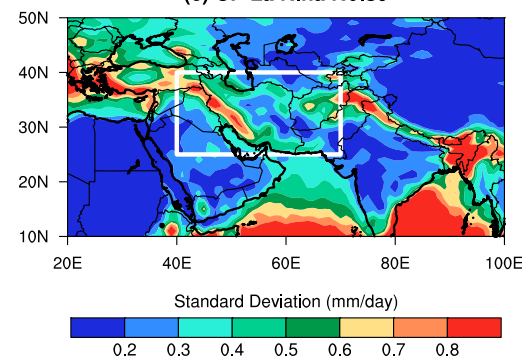

(f) EP La Nina Noise

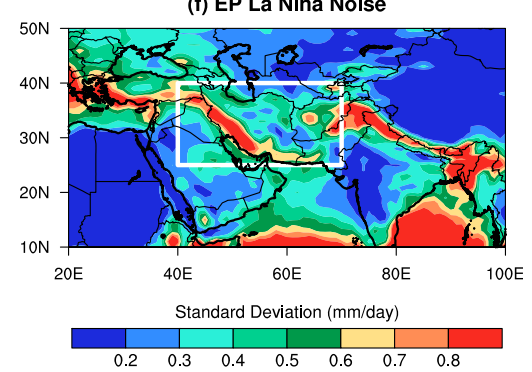

FIG. 6. November-April simulated (left column) signal-to-noise ratio, (center column) precipitation anomaly (mm day ${ }^{-1}$ ), and (right column) precipitation std dev ( $\mathrm{mm} \mathrm{day}^{-1}$ ) during (top row) CP La Niña and (bottom row) EP La Niña. Precipitation anomalies are significant at $p<0.05$ according to a two-sided $t$ test.

unpredictable noise during CP La Niña across southwest Asia, it is important to note that atmospheric noise can still exert an important effect on the regional precipitation. The effect of atmospheric noise can therefore reinforce the precipitation signal and produce drier conditions over southwest Asia, and in a less likely scenario, oppose the precipitation signal and even produce wet conditions over southwest Asia.

By contrast, near-zero region-wide signal-to-noise ratios across southwest Asia in the ensemble of model simulations (Fig. 6d) demonstrate that EP La Niña offers no precipitation predictability. The near-zero signal-to-noise ratios during EP La Niña (Fig. 6d) are a result of the small and statistically insignificant precipitation signal across southwest Asia, the Arabian Peninsula, and the Middle East in the ensemble of model simulations (Fig. 6e) relative to the notable precipitation noise component (Fig. 6f). The lack of precipitation predictability during EP La Niña is therefore a result of the precipitation spread from atmospheric noise overwhelming the small forced precipitation signal.

The large forced below-average precipitation signal during CP La Niña relative to the effect of atmospheric noise on precipitation in the atmospheric model simulations results in an increase in the probability of southwest Asia precipitation falling into the low tercile (Fig. 7a) and a decrease in the probability of precipitation falling into the upper tercile (Fig. 7c) relative to chance. The probability of precipitation falling into the low tercile is greater than $60 \%$ throughout most of southwest Asia, and greater than $70 \%$ over Afghanistan, Pakistan, and southwestern Iran (Fig. 7a). These large increases in the probability of below-tercile precipitation during CP La Niña are compensated by decreases in the probabilities of both middle- and upper-tercile precipitation (Figs. $7 \mathrm{~b}, \mathrm{c}$ ). The probability that precipitation falls into the upper tercile is less than $10 \%$ across much of southwest Asia (Fig. 7c), while the probability that precipitation falls into the middle tercile is between $20 \%$ and $30 \%$. By contrast, EP La Niña hardly changes the probability of southwest Asia precipitation falling into the low, middle, and upper terciles of the historical precipitation distribution during November-April from what one would expect from chance (Figs. 7d-f) by virtue of the unpredictable precipitation spread overwhelming the near-zero forced precipitation signal.

\section{2) Circulation}

We are motivated to better understand the tropical forcing of cold season southwest Asia precipitation, and how CP and EP La Niña condition the tropical Indo-Pacific features that may be important to the predictability of the region. We focus on the hypothesized relationship between southwest Asia climate and tropical eastern Indian Ocean and Maritime Continent diabatic heating (using precipitation anomalies 
(a) CP La Nina Lower Tericle

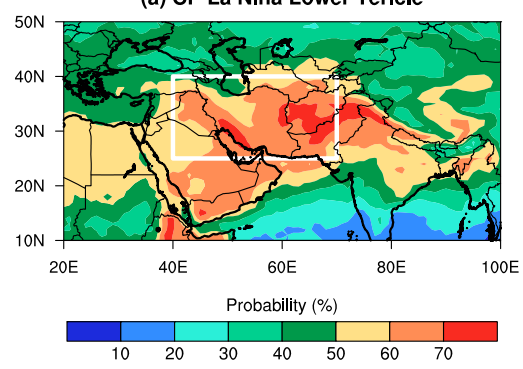

(d) EP La Nina Lower Tercile

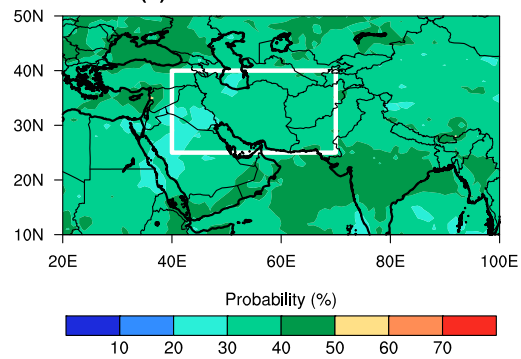

(b) CP La Nina Middle Tericle

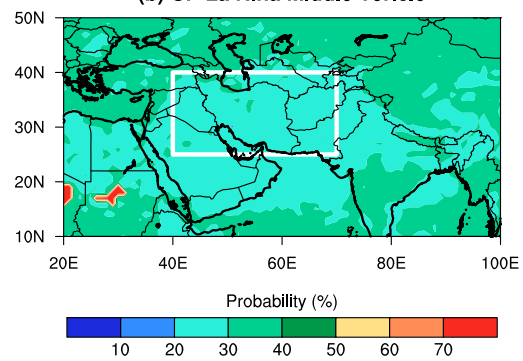

(e) EP La Nina Middle Tercile

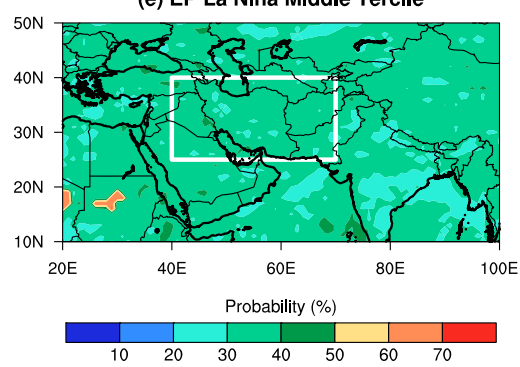

(c) CP La Nina Upper Tercile

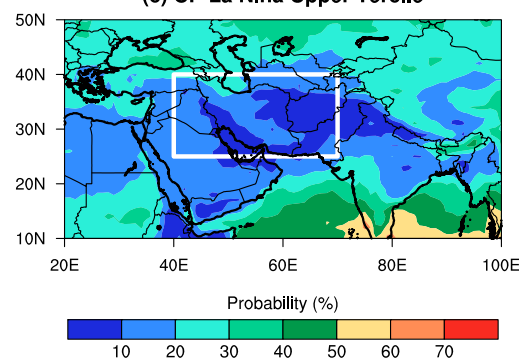

(f) EP La Nina Upper Tercile

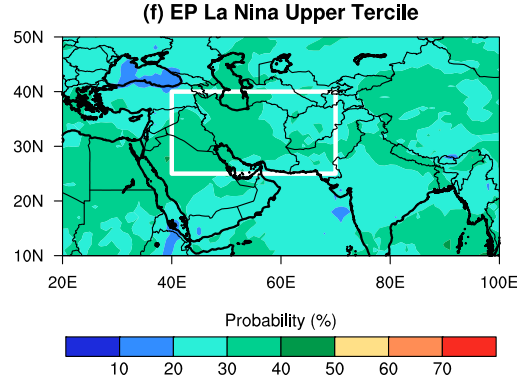

FIG. 7. November-April simulated probability of precipitation falling in the (left column) lower tercile, (center column) middle tercile, and (right column) upper tercile during (top row) CP La Niña and (bottom row) EP La Niña.

as a proxy) that has been developed through observational (e.g., Barlow et al. 2002; Hoell et al. 2013; Hoell and Funk 2013) and modeling studies (e.g., Barlow et al. 2007; Hoell et al. 2014a, 2015b). This hypothesis postulates that enhanced (reduced) tropical eastern Indian Ocean and Maritime Continent precipitation is related with warm core anticyclonic (cold core cyclonic) Rossby waves over Asia that are then related with reduced (enhanced) southwest Asia precipitation. The warm core (cold core) Rossby waves interact with the mean zonal wind to produce anomalous cold (warm) horizontal temperature advection over southwest Asia that is balanced by anomalous subsidence (ascent), which in turn modifies the regional precipitation. To that end, we compare composites of the simulated $300-$ and $850-\mathrm{hPa}$ wind, precipitation, and precipitable water anomalies when southwest Asia precipitation falls into the lower and upper terciles during November-April of CP and EP La Niña events in order to ascertain whether the previously identified key mechanisms are present.

The differences between the simulated composites of lower- and upper-tercile southwest Asia precipitation during La Niña support the hypothesis that eastern Indian Ocean and southwest Asia precipitation are closely related, specifically that enhanced (reduced) eastern Indian Ocean precipitation coincides with reduced (enhanced) southwest Asia precipitation (cf. Figs 8a,c and $8 b, d$ ). The enhanced (reduced) eastern Indian Ocean precipitation that coincides with reduced (enhanced) southwest Asia precipitation will hereafter be referred to as an inverse relationship.

Lower-tercile southwest Asia precipitation during both CP and EP La Niña (Figs. 8a,c), in which an anomalous upper-tropospheric anticyclonic circulation extends across Asia, is related with enhanced eastern Indian Ocean and Maritime Continent precipitation. Lower-tercile southwest Asia precipitation during both CP and EP La Niña is also related with anomalous lower-tropospheric northerly flow away from southwest Asia as well as negative anomalies in precipitable water that aid in the reduction of the regional precipitation (Figs. 9a,c). Upper-tercile southwest Asia precipitation during both $\mathrm{CP}$ and $\mathrm{EP}$ La Niña (Figs. 8b,d) is related with reduced eastern Indian Ocean precipitation anomalies, yet enhanced Maritime Continent precipitation anomalies. While the key aspect here is that tropical eastern Indian Ocean precipitation anomalies are inversely related with southwest Asia precipitation, Maritime Continent precipitation anomalies of the same sign as the eastern Indian Ocean produce a stronger and more widespread southwest Asia precipitation response during La Niña. Also noteworthy during instances of upper-tercile southwest Asia precipitation occurrences during both CP and EP La Niña is anomalous lower-tropospheric southerly flow into southwest Asia, as well as positive anomalies in precipitable water that aid in the enhancement of the regional precipitation (Figs. 9b,d). 
(a) CP La Nina Southwest Asia Lower Tercile

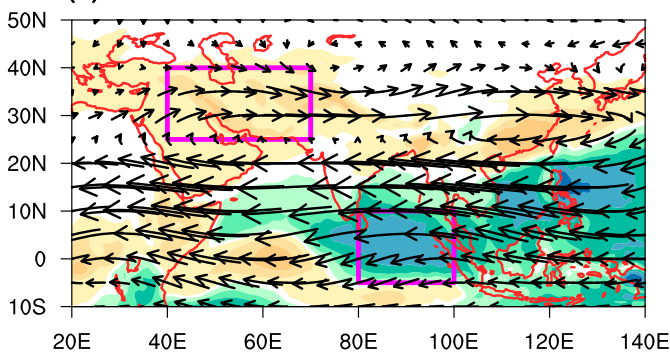

(c) EP La Nina Southwest Asia Lower Tercile

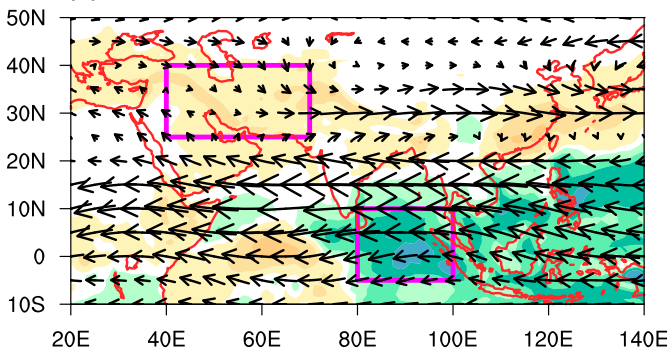

(b) CP La Nina Southwest Asia Upper Tercile

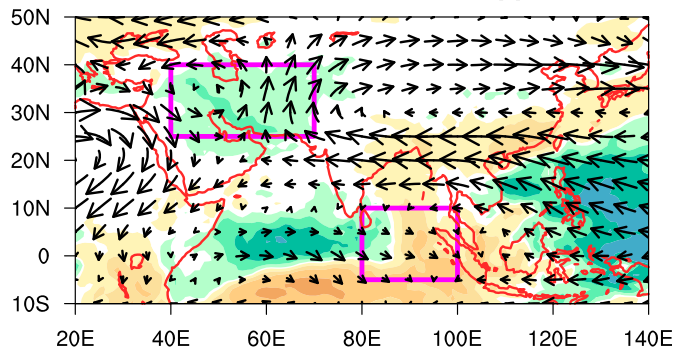

(d) EP La Nina Southwest Asia Upper Tercile

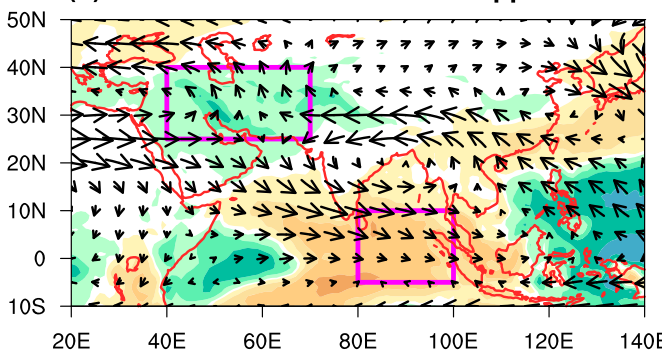

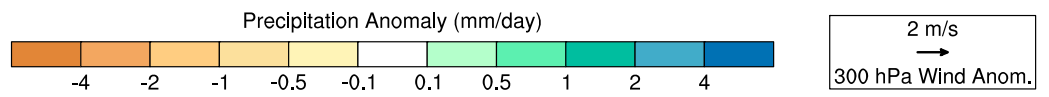

FIG. 8. November-April simulated 300-hPa wind anomaly (vector; $\mathrm{m} \mathrm{s}^{-1}$ ) and precipitation anomaly (shading; $\mathrm{mm} \mathrm{day}^{-1}$ ) when areally averaged simulated southwest Asia precipitation falls in the (left column) lower tercile and (right column) upper tercile during (top row) CP La Niña and (bottom row) EP La Niña. Precipitation anomalies are significant at $p<0.05$ according to a two-sided $t$ test.

\section{3) SOUTHWESt ASIA AND Indian OCEAN PRECIPITATION RELATIONSHIP}

We further probe the apparent inverse relationship between tropical eastern Indian Ocean and southwest Asia precipitation through scatter diagrams of simulated areally averaged eastern Indian Ocean precipitation anomalies $\left(5^{\circ} \mathrm{S}-10^{\circ} \mathrm{N}, 80^{\circ}-100^{\circ} \mathrm{E}\right)$ and southwest Asia precipitation anomalies during ENSO neutral, CP La Niña, and EP La Niña in the ensemble of model simulations (Fig. 10, top row). These scatter diagrams indicate that statistically significant inverse relationships $(p<0.05)$, with correlations ranging from 0.55 to 0.63 , exist between tropical eastern Indian Ocean precipitation and southwest Asia precipitation anomalies during November-April. Additionally, this relationship is also robust during ENSO neutral conditions, thereby indicating that ENSO is not a necessary condition for the hypothesized tropical forcing of southwest Asia precipitation on seasonal time scales. This is consistent with a range of dynamical experiments that have shown that tropical forcing in the eastern Indian Ocean results in a Gill-Matsuno-like Rossby response over southwest Asia in a baroclinic linear model (Barlow et al. 2002), an atmospheric model (Barlow et al. 2007), and a two-layer shallow-water model (Barlow 2011), where the twolayer model results suggested that interaction of the Rossby response with the mean flow is important in determining the latitude of the response. Though a statistically significant relationship exists between precipitation over southwest Asia and the eastern Indian Ocean, notable variability is still present in this relationship, as the correlation between the two variables indicates only $\sim 35 \%$ variance explained. While enhanced (reduced) eastern Indian Ocean precipitation is most commonly related with reduced (enhanced) southwest Asia precipitation, it must be noted that there are exceptions.

While our results support the hypothesis that tropical eastern Indian Ocean precipitation is inversely related with cold season southwest Asia precipitation during both La Niña and ENSO neutral, an important question that remains is how the two types of La Niña condition the probabilities of eastern Indian Ocean precipitation anomalies, and how these changes then affect southwest Asia precipitation anomalies. To that end, twodimensional histograms of eastern Indian Ocean and southwest Asia precipitation are constructed in the ensemble of model simulations (Fig. 10, bottom row). CP La Niña greatly increases the probability of enhanced 
(a) CP La Nina Southwest Asia Lower Tercile

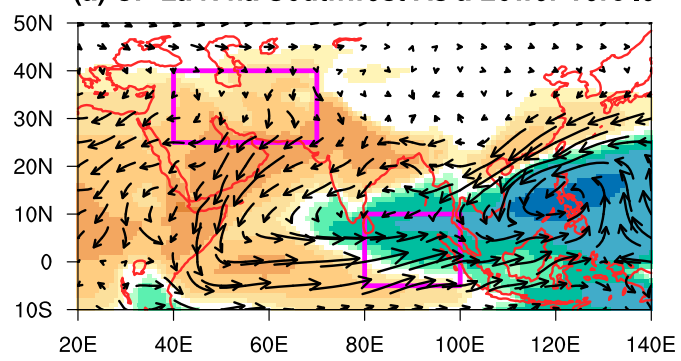

(c) EP La Nina Southwest Asia Lower Tercile

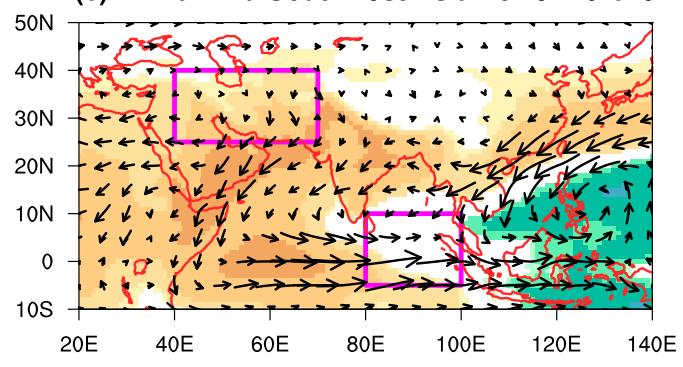

(b) CP La Nina Southwest Asia Upper Tercile

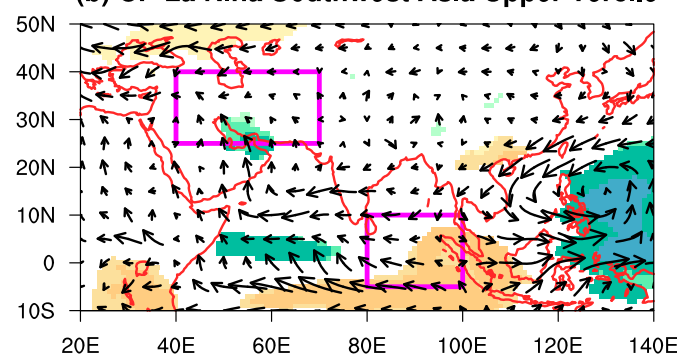

(d) EP La Nina Southwest Asia Upper Tercile

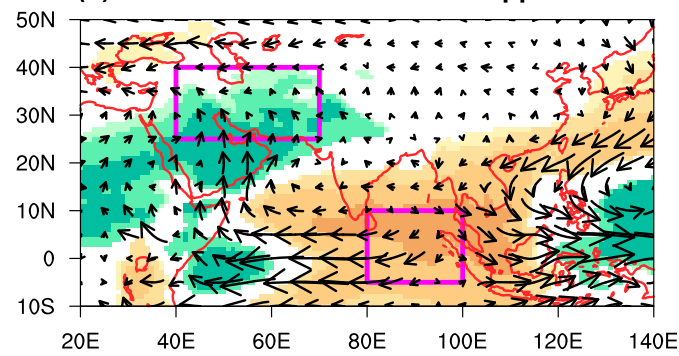

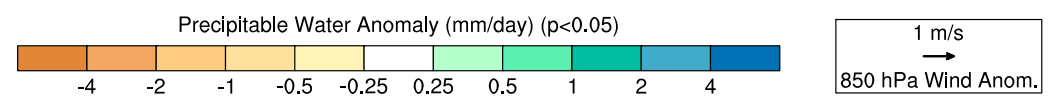

FIG. 9. November-April simulated $850-\mathrm{hPa}$ wind anomaly (vector; $\mathrm{m} \mathrm{s}^{-1}$ ) and precipitable water anomaly (shading; $\mathrm{mm} \mathrm{day}^{-1}$ ) when areally averaged simulated southwest Asia precipitation falls in the (left column) lower tercile and (right column) upper tercile during (top row) CP La Niña and (bottom row) EP La Niña. Precipitable water anomalies are significant at $p<0.05$ according to a two-sided $t$ test.

eastern Indian Ocean precipitation and reduced southwest Asia precipitation relative to ENSO neutral (cf. Figs. 10d and 10b), whereas EP La Niña is unrelated with changes in the probabilities of eastern Indian Ocean precipitation and southwest Asia precipitation relative to ENSO neutral (cf. Figs. 10f and 10b).

The effectiveness of CP La Niña in producing enhanced eastern Indian Ocean precipitation and therefore dry conditions over southwest Asia compared with EP La Niña is likely due to the differences in the SST anomaly patterns between these two La Niña types. The SST anomaly pattern of CP La Niña is characterized by much stronger cold anomalies than EP La Niña, and is highlighted by a sharp gradient of anomalous SSTs between the west and central Pacific Ocean. Our results suggest that the CP La Niña SST anomaly pattern provides for a higher probability of producing atmospheric forcing in a location (i.e., the eastern Indian Ocean) to which southwest Asia is sensitive. The important effect of a sharp anomalous SST gradient between the west and central Pacific Ocean on atmospheric teleconnections, both globally and over southwest Asia, has been highlighted by Hoell and Funk (2013). By contrast, our results also suggest that the SST anomaly pattern of EP La Niña does not provide for a higher probability of producing atmospheric forcing over the tropical eastern Indian Ocean that in turn affects southwest Asia precipitation.

\section{b. El Niño}

\section{1) Precipitation PRedictability}

Signal-to-noise ratios of near 0.7 standard deviations in the ensemble of model simulations over the high elevations of Iran, Afghanistan, and Pakistan suggest that both EP and CP El Niño offer similar levels of southwest Asia precipitation predictability during NovemberApril (Figs. 11a,d). The precipitation signals during EP and CP El Niño are positive throughout the region, and are particularly strong over the same areas in which signal-to-noise ratios are also largest (Figs. 11b,e). The magnitude and pattern of the precipitation signals in the ensemble of model simulations (Figs. 11b,e) are similar to the average observed precipitation anomaly during all El Niño events after 1979 (Fig. 1a). The precipitation noise during EP and CP El Niño is important throughout the region, and its magnitude overwhelms that of the signal over many low-lying regions, as evidenced by signal-to-noise ratios of just 0.3 over the Arabian Peninsula and central Iran. An important distinction between EP and CP El Niño is that EP El Niño is related 
(a) ENSO Neutral, $r=-0.55$

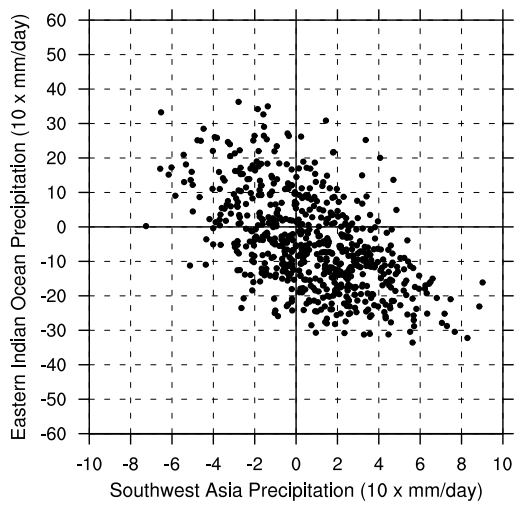

(b) ENSO Neutral Histogram

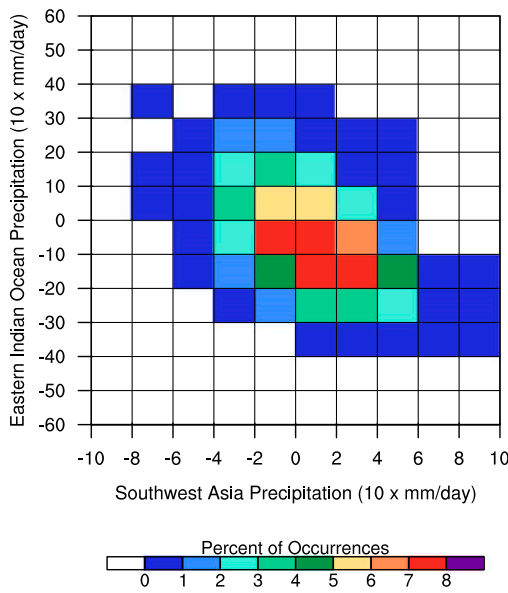

(c) CP La Nina Precipitation Scatter, r=-0.57

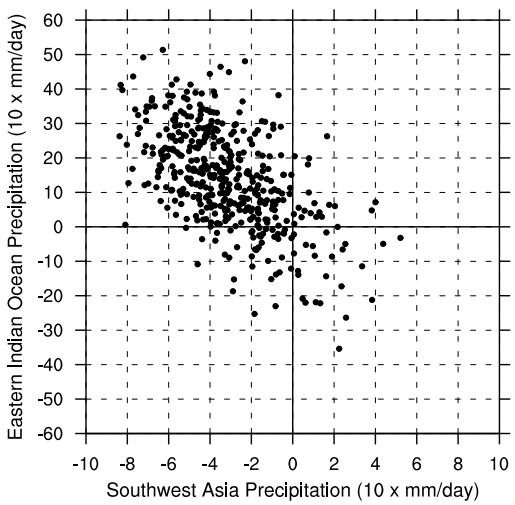

(d) CP La Nina Histogram

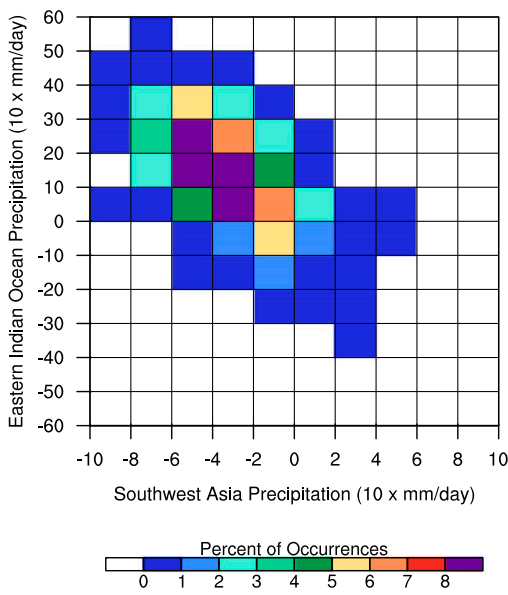

(e) EP La Nina Precipitation Scatter, $r=-0.63$

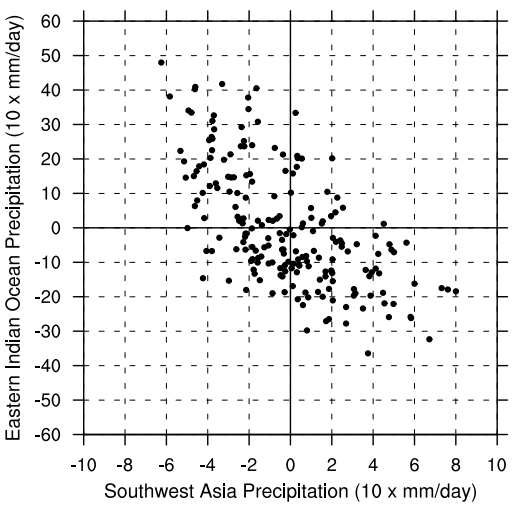

(f) EP La Nina Histogram

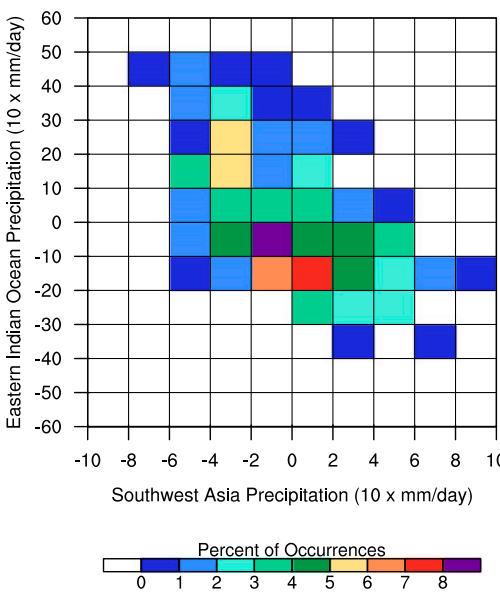

FIG. 10. November-April simulated (top row) scatter diagram and (bottom row) two-dimensional histogram of eastern Indian Ocean precipitation anomaly (ordinate; $10 \times \mathrm{mm} \mathrm{day}^{-1}$ ) and southwest Asia precipitation anomaly (abscissa; $10 \times \mathrm{mm} \mathrm{day}^{-1}$ ) during $($ left column) ENSO neutral, (center column) CP La Niña, and (right column) EP La Niña.

with slightly greater signal-to-noise ratios through the region because the magnitude of the noise is lower (cf. Figs. 11c and 11f). These results suggest that the boundary conditions drive a similar, yet important, response over southwest Asia during EP and CP El Niño that provides some predictability. However, it must be noted that atmospheric noise is considerable and exerts an important effect on the regional precipitation during $\mathrm{El} \mathrm{Niño,} \mathrm{in} \mathrm{the} \mathrm{form} \mathrm{of} \mathrm{either} \mathrm{intensified} \mathrm{wetness} \mathrm{or} \mathrm{a}$ less likely reversal of precipitation sign to dryness.

EP and CP El Niño similarly modify the probabilities of November-April southwest Asia precipitation falling into the lower, middle, and upper terciles relative to chance in the ensemble of model simulations (Fig. 12). Both EP and CP El Niño decrease the probability of lower-tercile precipitation to less than $20 \%$ region-wide, with EP El Niño decreasing those probabilities even further to less than $10 \%$ over areas of Afghanistan, Pakistan, and Iran (Figs. 12a,d). By contrast, EP and CP El Niño increase the probability of upper-tercile precipitation to greater than $50 \%$ across much of the region, except for the lower elevations of Iran where the probabilities are around $45 \%$ (Figs. 12c,f). The probabilities of middle-tercile precipitation during EP and CP El Niño do not deviate much from what is expected by random chance, as probabilities are found to be between $30 \%$ and $40 \%$ region-wide (Figs. 12b,e).

\section{2) Circulation}

In a similar fashion as our analysis of EP and CP La Niña, we examine how EP and CP El Niño condition tropical Indo-Pacific features that may be important to the predictability of cold season southwest Asia precipitation. We again focus on the hypothesized relationship between southwest Asia precipitation and circulation and tropical eastern Indian Ocean and Maritime Continent precipitation through a comparison of simulated 300- and 850-hPa wind, precipitation, and precipitable water composite anomalies when southwest Asia precipitation falls into the lower and upper terciles 
(a) CP EI Nino Signal-to-Noise Ratio

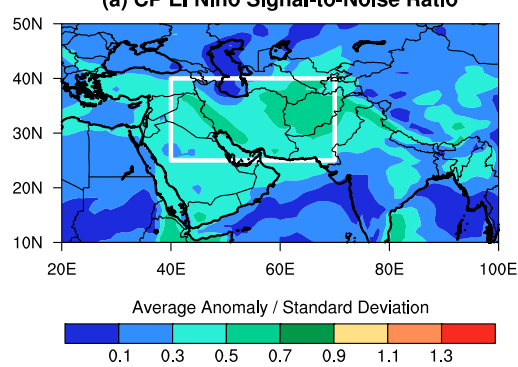

(d) EP EI Nino Signal-to-Noise Ratio

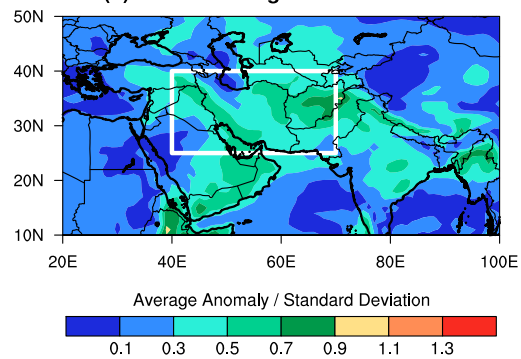

(b) CP EI Nino Signal

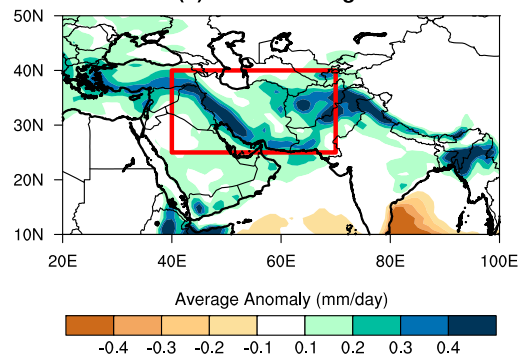

(e) EP El Nino Signal

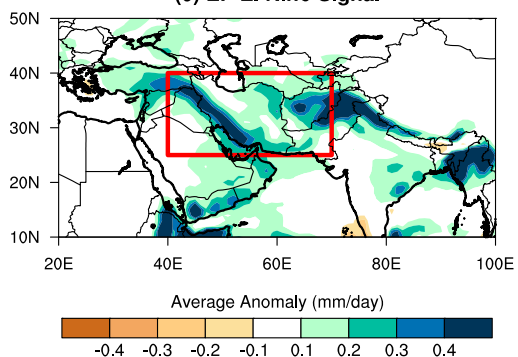

(c) CP El Nino Noise

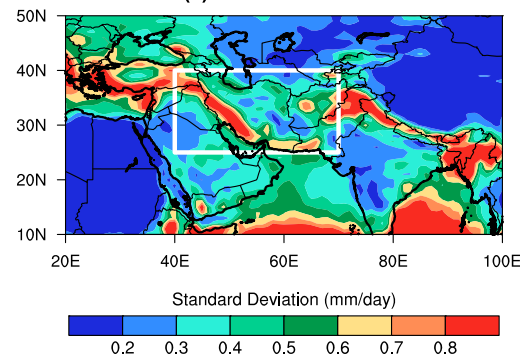

(f) EP EI Nino Noise

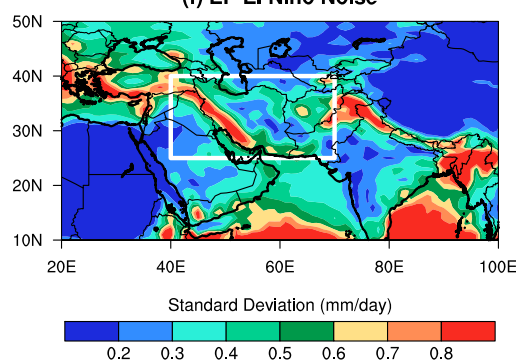

FIG. 11. November-April simulated (left column) signal-to-noise ratio, (center column) precipitation anomaly ( $\mathrm{mm} \mathrm{day}^{-1}$ ), and (right column) precipitation std dev (mm day ${ }^{-1}$ ) during (top row) CP El Niño and (bottom row) EP El Niño. Precipitation anomalies are significant at $p<0.05$ according to a two-sided $t$ test.

during November-April of CP and EP El Niño. Again, this hypothesis postulates that enhanced (reduced) tropical eastern Indian Ocean and Maritime Continent precipitation is related with warm core anticyclonic (cold core cyclonic) Rossby waves over Asia that are then related with reduced (enhanced) southwest Asia precipitation. The warm core (cold core) Rossby waves interact with the mean zonal wind to produce anomalous cold (warm) horizontal temperature advection over southwest Asia that is balanced by anomalous subsidence (ascent), which in turn modifies the regional precipitation. (a) CP EI Nino Lower Tericle

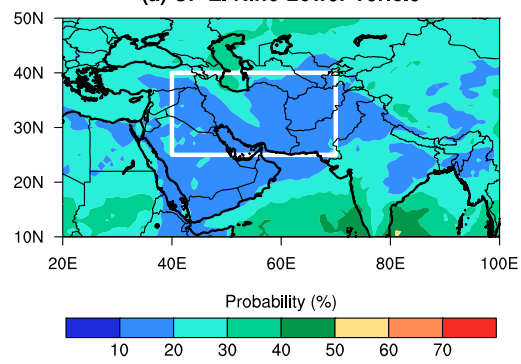

(d) EP El Nino Lower Tercile

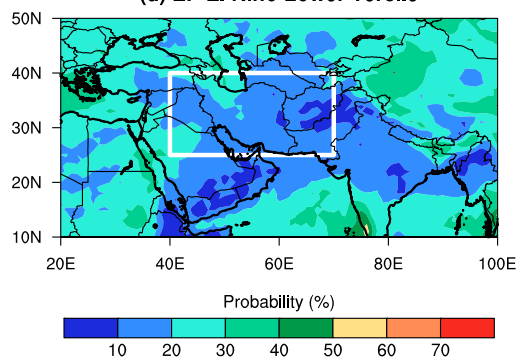

(b) CP El Nino Middle Tericle

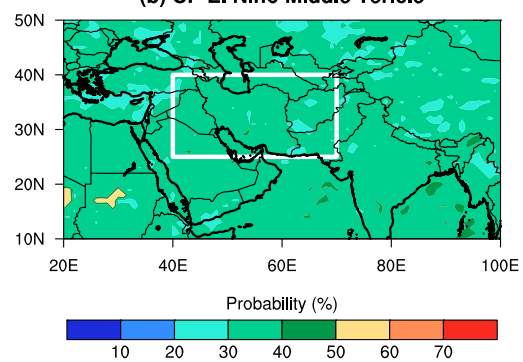

(e) EP EI Nino Middle Tercile

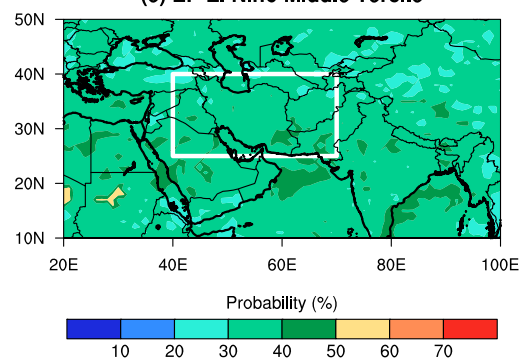

(c) CP El Nino Upper Tercile

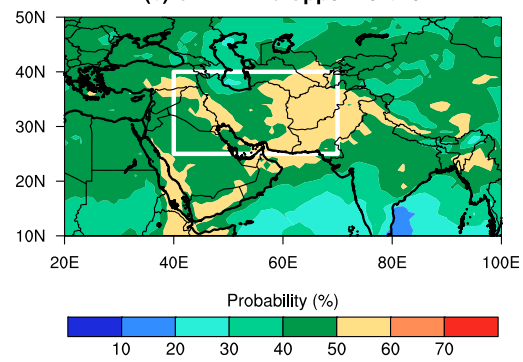

(f) EP El Nino Upper Tercile

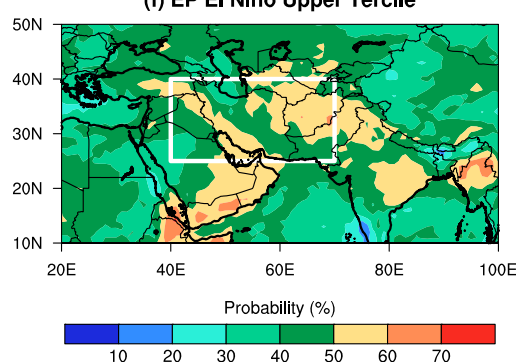

FIG. 12. November-April simulated probability of precipitation falling in the (left column) lower tercile, (center column) middle tercile, and (right column) upper tercile during (top row) CP El Niño and (bottom row) EP El Niño. 
(a) CP EI Nino Southwest Asia Lower Tercile

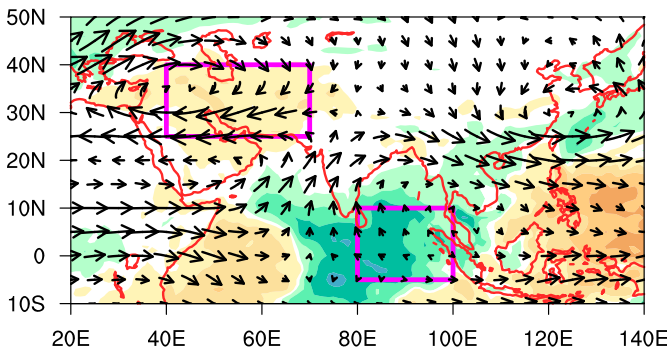

(c) EP El Nino Southwest Asia Lower Tercile

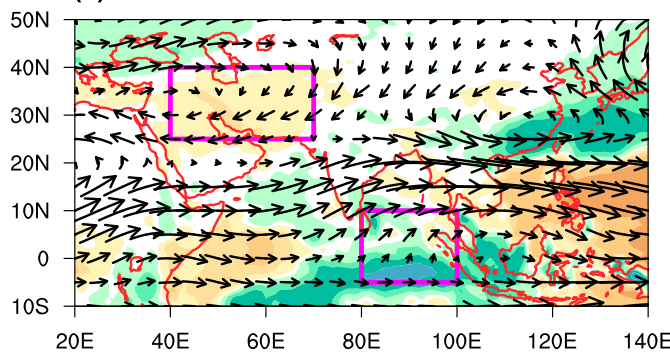

(b) CP El Nino Southwest Asia Upper Tercile

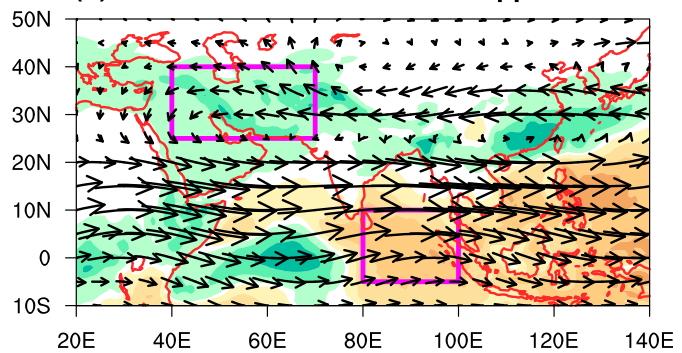

(d) EP EI Nino Southwest Asia Upper Tercile

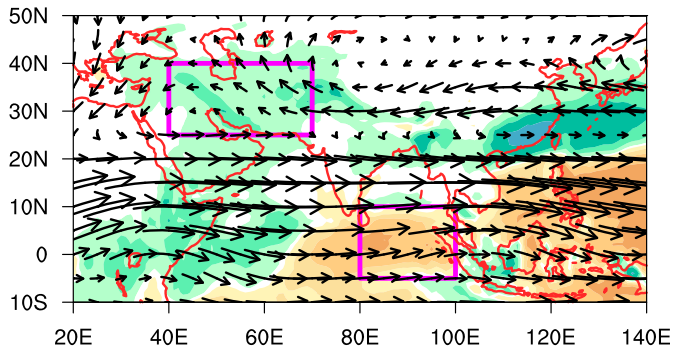

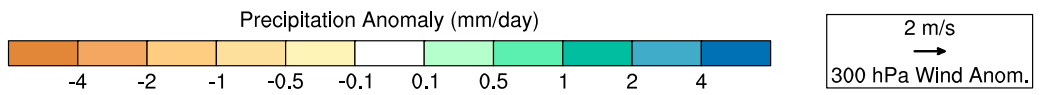

FIG. 13. November-April simulated 300-hPa wind anomaly (vector; $\mathrm{m} \mathrm{s}^{-1}$ ) and precipitation anomaly (shading; $\mathrm{mm} \mathrm{day}{ }^{-1}$ ) when areally averaged simulated southwest Asia precipitation falls in the (left column) lower tercile and (right column) upper tercile during (top row) CP El Niño and (bottom row) EP El Niño. Precipitation anomalies are significant at $p<0.05$ according to a two-sided $t$ test.

\section{3) SOUTHWEST ASIA AND INDiAn OCEAN PRECIPITATION RELATIONSHIP}

The differences between the simulated composites of lower- and upper-tercile southwest Asia precipitation during El Niño also support the hypothesis that tropical eastern Indian Ocean and southwest Asia precipitation are inversely related. Upper-tercile southwest Asia precipitation during both CP and EP El Niño (Figs. 13b,d), in which an anomalous upper-tropospheric cyclonic circulation extends across Asia, is related with reduced eastern Indian Ocean and Maritime Continent precipitation. Furthermore, uppertercile southwest Asia precipitation during both $\mathrm{CP}$ and EP El Niño (Figs. 14b,d) is related with anomalous lowertropospheric southerly flow toward southwest Asia as well as positive anomalies in precipitable water that aid in the enhancement of the regional precipitation. Lower-tercile southwest Asia precipitation during both $\mathrm{CP}$ and $\mathrm{EP} \mathrm{El}$ Niño (Figs. 13a,c), in which anomalous upper-tropospheric northerly flow is present over southwest Asia, is related with enhanced eastern Indian Ocean precipitation anomalies, yet reduced Maritime Continent precipitation anomalies. Lower-tercile southwest Asia precipitation during both CP and EP El Niño (Figs. 14a,c) is also related with anomalous lower-tropospheric northerly flow away from southwest
Asia, as well as negative anomalies in precipitable water that aid in the reduction of the regional precipitation. These results suggest that tropical eastern Indian Ocean precipitation anomalies play a key role in determining southwest Asia precipitation, and that Maritime Continent precipitation anomalies of the same sign as the eastern Indian Ocean produce a stronger and more widespread southwest Asia precipitation response during both El Niño and La Niña.

The inverse relationship between tropical eastern Indian Ocean and southwest Asia precipitation during La Niña and ENSO neutral (Fig. 9, top row) also occurs during CP El Niño and EP El Niño in the ensemble of model simulations (Fig. 15, top row). Scatter diagrams show that a statistically significant inverse relationship, with correlations around 0.50 , exists between tropical eastern Indian Ocean precipitation and southwest Asia precipitation anomalies during November-April of both EP and CP El Niño events. The results during El Niño, La Niña, and ENSO neutral demonstrate that the inverse relationship between eastern Indian Ocean precipitation and southwest Asia precipitation is an important feature regardless of ENSO state.

While CP La Niña greatly increases the probability of enhanced eastern Indian Ocean precipitation and reduced southwest Asia precipitation relative to ENSO 
(a) CP EI Nino Southwest Asia Lower Tercile

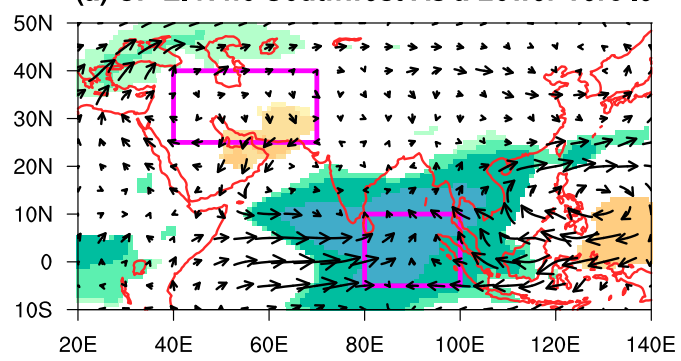

(c) EP El Nino Southwest Asia Lower Tercile

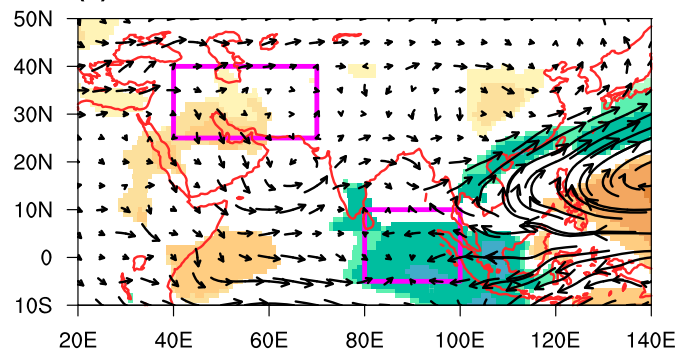

(b) CP EI Nino Southwest Asia Upper Tercile

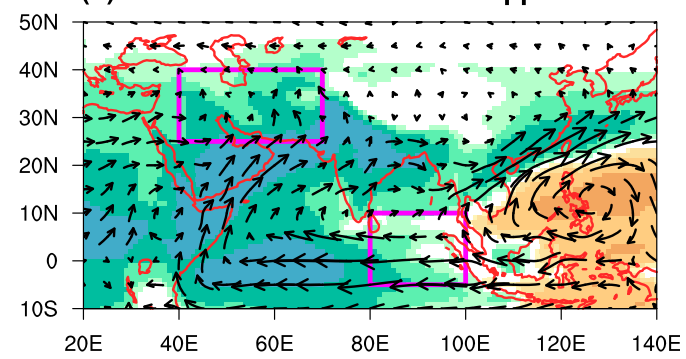

(d) EP El Nino Southwest Asia Upper Tercile

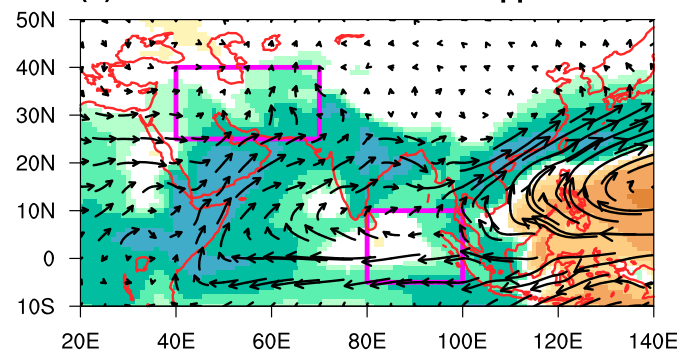

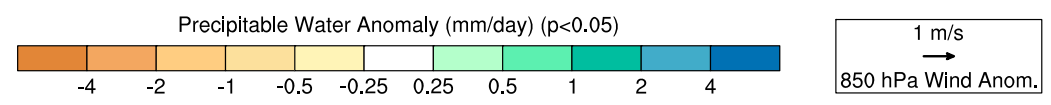

FIG. 14. November-April simulated 850-hPa wind anomaly (vector; $\mathrm{m} \mathrm{s}^{-1}$ ) and precipitation anomaly (shading; mm day ${ }^{-1}$ ) when areally averaged simulated southwest Asia precipitation falls in the (left column) lower tercile and (right column) upper tercile during (top row) CP El Niño and (bottom row) EP El Niño. Precipitable water anomalies are significant at $p<0.05$ according to a two-sided $t$ test.

neutral (cf. Figs. 9d and 9b), both CP and EP El Niño do the opposite (Figs. 14d,f). That is, CP and EP El Niño increase the probability of reduced eastern Indian Ocean precipitation and enhanced southwest Asia precipitation relative to ENSO neutral (cf. Figs. 14d,f and 14b). Since EP and CP El Niño result in similar simulated probabilities of reduced eastern Indian Ocean precipitation and wet conditions over southwest Asia, this suggests that the SST anomaly patterns of both El Niño types are equally effective in forcing the atmosphere for the purposes of modifying southwest Asia precipitation and circulation. This is a noteworthy finding because the patterns and magnitudes of the SST anomalies associated with EP and CP El Niño are visually quite different (Fig. 5). Despite the differences, two similarities stand out: the warm central Pacific SST anomaly along the date line and the warm Indian Ocean SST anomalies. From this, we pose the question: are these two aspects of the SST anomaly pattern key to the atmospheric response to El Niño?

\section{Summary and discussion}

We have estimated the sensitivity of cold season southwest Asia precipitation to four types of ENSO using a 50-member ensemble of atmospheric model simulations forced by 1979-2015 observed boundary conditions. Our assessment focused on examining the unpredictable spread of possible southwest Asia precipitation around the predictable signal during the four types of ENSO, and their tropical-extratropical dynamical links in the context of existing hypotheses. The four ENSO types investigated were EP El Niño, CP El Niño, EP La Niña, and CP La Niña. This analysis provides an assessment of the range of southwest precipitation outcomes associated with ENSO, both in terms of signal-to-noise ratios and tercile probabilities, and demonstrates that the ENSO type is critical to understanding the nature of the El Niño and La Niña responses.

The magnitude of the below-average predictable precipitation signal across southwest Asia and the southern half of the Arabian Peninsula matches and exceeds the magnitude of the unpredictable precipitation spread during November-April of CP La Niña. As a consequence, the probability that southwest Asia precipitation falls into the lower tercile of the historical precipitation distribution is greater than $60 \%$ region-wide, and greater than $70 \%$ over Afghanistan and Pakistan. However, despite the relative magnitudes of the predictable signal to unpredictable noise during 
(a) ENSO Neutral, $r=-0.55$

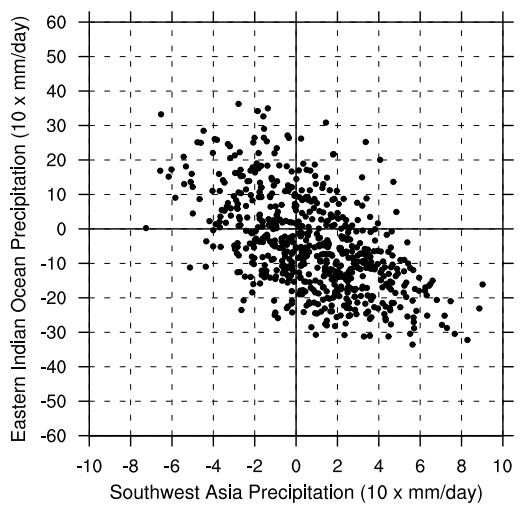

(b) ENSO Neutral Histogram

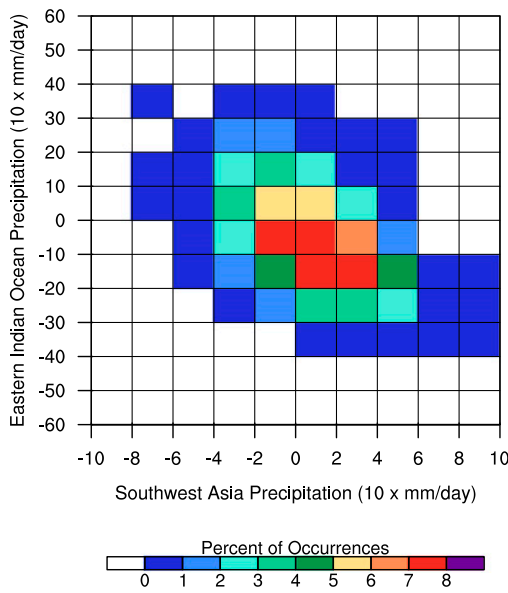

(c) CP El Nino Precipitation Scatter, r=-0.52

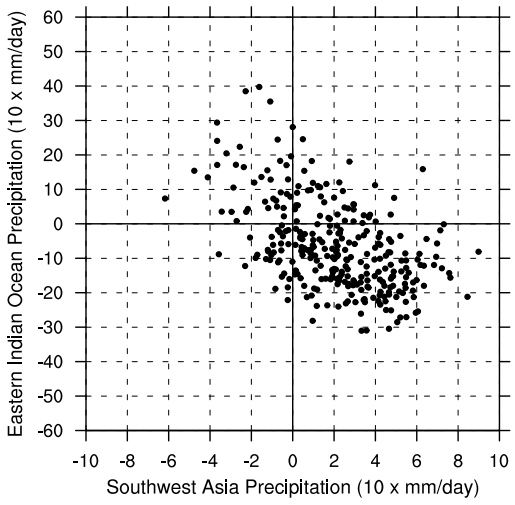

(d) CP La Nina Histogram

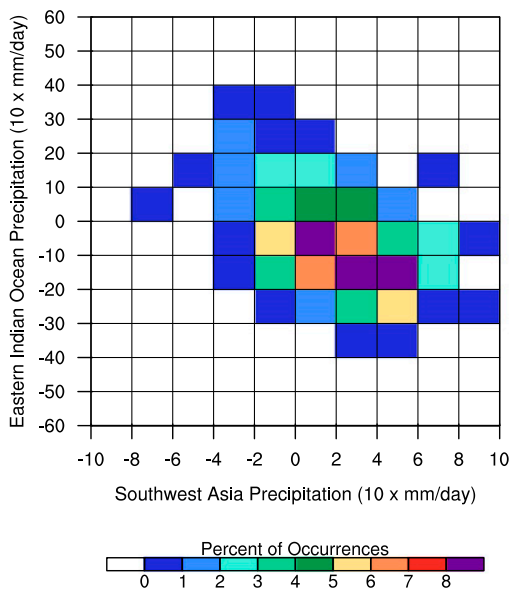

(e) EP El Nino Precipitation Scatter, $r=-0.49$

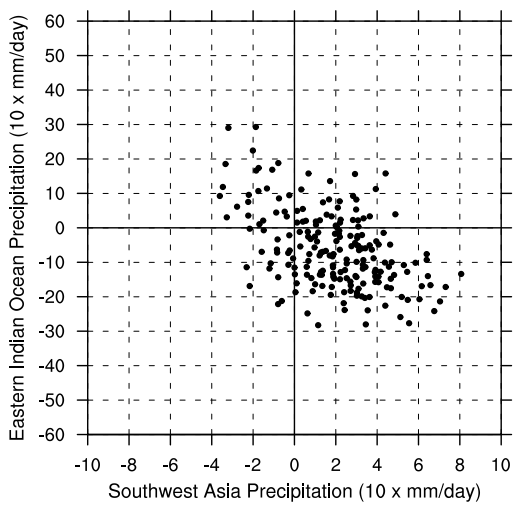

(f) EP La Nina Histogram

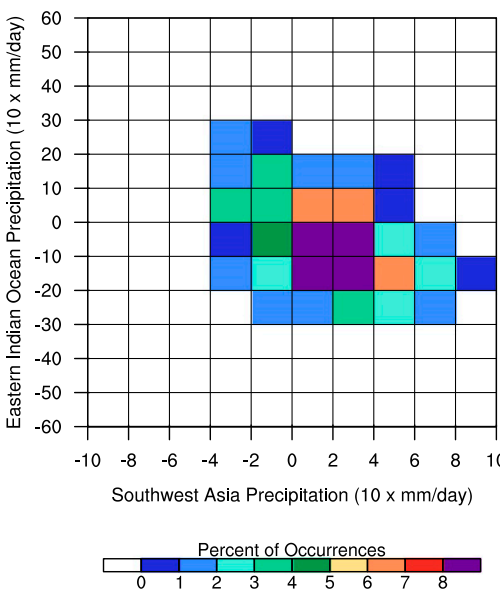

FIG. 15. November-April simulated (top row) scatter diagram and (bottom row) two-dimensional histogram of eastern Indian Ocean precipitation anomaly (ordinate; $10 \times \mathrm{mm} \mathrm{day}^{-1}$ ) and southwest Asia precipitation anomaly (abscissa; $10 \times \mathrm{mm} \mathrm{day}^{-1}$ ) during $($ left column) ENSO neutral, (center column) CP El Niño, and (right column) EP El Niño.west

CP La Niña, it is important to note that atmospheric noise can still exert an important effect on southwest Asia precipitation. The effect of the unpredictable spread therefore allows for a near $10 \%$ probability that precipitation falls into the upper tercile of the historical southwest Asia precipitation distribution during CP La Niña. By contrast, EP La Niña offers no southwest Asia precipitation predictability, as the magnitude of the unpredictable precipitation spread overwhelms the near-zero forced predictable precipitation signal.

The magnitudes of the above-average predictable precipitation signals approach the magnitudes of the unpredictable precipitation spreads during both EP and CP El Niño. While EP and CP El Niño provide some predictability of southwest Asia precipitation, and increase the probability of above-tercile precipitation to around $50 \%$ region-wide, the effect of atmospheric noise is considerable. The effect of atmospheric noise therefore allows for a near $20 \%$ probability of southwest Asia precipitation falling into the lower tercile.
The key to constraining the possible precipitation outcomes over southwest Asia is a better understanding of the commingling of variability internal to the atmosphere with the ENSO-forced signal. To that end, this study can be used to assess the probabilities of seasonal precipitation over southwest Asia based upon the state of ENSO. However, the growing body of literature that examines effects of the NAO and MJO on southwest Asia, for example, perform these studies in isolation and ignore possible ENSO effects largely due to sampling constraints. A better understanding of southwest Asia weather and climate resides in a more holistic approach; that is, consideration of how all drivers of the regional variability come together and produce precipitation outcomes. A more holistic approach can be applied as data records lengthen, as models improve, and as we identify new ways to exploit existing model simulations.

We also examined how the tropical atmosphere over the Indian and Pacific Oceans aids in communicating the 
forcing of the SST patterns associated with the four ENSO types to southwest Asia. We focused on the hypothesized relationship that enhanced (reduced) tropical eastern Indian Ocean and Maritime Continent precipitation is related with Rossby waves over Asia that reduce (enhance) southwest Asia precipitation.

Our results affirm the hypothesis that anomalous tropical eastern Indian Ocean and southwest Asia precipitation are inversely related. On average, when anomalous Indian Ocean and Maritime Continent precipitation have the same sign, an anomalous uppertropospheric Rossby wave extends over much of southern Asia, resulting in strong and widespread changes to southwest Asia precipitation. Enhanced Indian Ocean and Maritime Continent precipitation is related with high pressure throughout Asia and negative precipitation departures over southwest Asia, while reduced Indian Ocean and Maritime Continent precipitation is related with low pressure throughout Asia and positive precipitation departures over southwest Asia. By contrast, when anomalous Indian Ocean and Maritime Continent precipitation have the opposite sign, the anomalous atmospheric circulation and precipitation are local to southwest Asia. Enhanced eastern Indian Ocean precipitation is related with anomalous northerly flow and precipitation deficits over southwest Asia, while reduced eastern Indian Ocean precipitation is related with anomalous southerly flow and precipitation surpluses over southwest Asia.

Each ENSO type conditions the probability of eastern Indian Ocean and southwest Asia precipitation anomalies differently. CP La Niña greatly increases the probability of enhanced eastern Indian Ocean precipitation and reduced southwest Asia precipitation, while EP La Niña is unrelated with changes in the probabilities of eastern Indian Ocean precipitation and southwest Asia precipitation. The SST anomaly pattern of CP La Niña is characterized by much stronger anomaly magnitudes than EP La Niña, and is highlighted by a sharp gradient of anomalous SSTs between the west and central Pacific Ocean, hypothesized to be an important driver of the global climate by Hoell and Funk (2013). Both EP and CP El Niño increase the probability of reduced eastern Indian Ocean precipitation and enhanced southwest Asia precipitation. The similar atmospheric effects of EP and CP El Niño are interesting because of the visual differences between the patterns of their SST anomalies. Despite the differences, two similarities stand out: the warm central Pacific SST anomaly along the date line and the warm Indian Ocean SST anomalies.

Key differences in the tropical and extratropical precipitation responses to SST anomalies associated with the different ENSO types imply key contributions by both SST anomaly magnitudes and patterns. However, it is currently unknown what parts of the Indo-Pacific Ocean, as well as their magnitudes, are most responsible for the forcing. To isolate the effects of certain IndoPacific Ocean SST areas on the southwest Asia climate, comparison of a suite of atmospheric model simulations forced by prescribed time-varying boundary conditions over specific areas would be necessary. Such a suite would include three separate experiments: 1) tropical Indo-Pacific SSTs are allowed to vary while SSTs elsewhere are held to climatological values, 2) tropical Indo-west Pacific SSTs are allowed to vary while SSTs elsewhere are held to climatological values, and 3) tropical eastern Pacific SSTs are allowed to vary while SSTs elsewhere are held to climatological values.

Our predictability assessment relies on an ensemble of atmospheric model simulations from which the necessary large number of samples can be drawn. While it is important to acknowledge the limitations of using an atmospheric model for this kind of analysis, this approach provides information that is not possible with the observational record. The model simulations are not a perfect substitute for observations, and inherent limitations of our study reside in possible unforeseen biases of the atmospheric model employed that were not captured in our model validation analysis, and the limited number of unique SST patterns due to the 1979-2015 analysis period. Nonetheless, the model simulations provide the opportunity to test the sensitivity of the southwest Asia climate to ENSO, in terms of both the roles of internal atmospheric variability and the SST patterns associated with ENSO itself.

Acknowledgments. The authors are grateful for support from the Famine Early Warning Systems Network and to Judith Perlwitz and Marty Hoerling for valuable feedback on the manuscript.

\section{REFERENCES}

Adler, R. F., and Coauthors, 2003: The Version-2 Global Precipitation Climatology Project (GPCP) monthly precipitation analysis (1979-present). J. Hydrometeor., 4, 1147-1167, https://doi.org/ 10.1175/1525-7541(2003)004<1147:TVGPCP $>2.0$. CO 2 .

Agrawala, S., M. Barlow, H. Cullen, and B. Lyon, 2001: The drought and humanitarian crisis in central and southwest Asia: A climate perspective. International Research Institute for Climate Prediction, 24 pp., https://doi.org/10.7916/D8NZ8FHQ.

Aizen, E. M., V. B. Aizen, J. M. Melack, T. Nakamura, and T. Ohta, 2001: Precipitation and atmospheric circulation patterns at mid-latitudes of Asia. Int. J. Climatol., 21, 535-556, https://doi.org/10.1002/joc.626.

Ashok, K., S. K. Behera, S. A. Rao, H. Weng, and T. Yamagata, 2007: El Niño Modoki and its possible teleconnection. J. Geophys. Res., 112, C11007, https://doi.org/10.1029/2006JC003798. 
Athar, H., 2015: Teleconnections and variability in observed rainfall over Saudi Arabia during 1978-2010. Atmos. Sci. Lett., 16, 373-379, https://doi.org/10.1002/asl2.570.

Barlow, M., 2011: The Madden-Julian oscillation influence on Africa and west Asia. Intraseasonal Variability in the Coupled Tropical Ocean-Atmosphere System, W. Lau and D. Waliser, Eds., Praxis, 477-493.

- H. Cullen, and B. Lyon, 2002: Drought in central and southwest Asia: La Niña, the warm pool, and Indian Ocean precipitation. J. Climate, 15, 697-700, https://doi.org/ 10.1175/1520-0442(2002)015<0697:DICASA > 2.0.CO;2.

- M. Wheeler, B. Lyon, and H. Cullen, 2005: Modulation of daily precipitation over southwest Asia by the MaddenJulian oscillation. Mon. Wea. Rev., 133, 3579-3594, https:// doi.org/10.1175/MWR3026.1.

— A. Hoell, and F. Colby, 2007: Examining the wintertime response to tropical convection over the Indian Ocean by modifying convective heating in a full atmospheric model. Geophys. Res. Lett., 34, L19702, https://doi.org/10.1029/2007GL030043.

—, B. Zaitchik, S. Paz, E. Black, J. Evans, and A. Hoell, 2016: A review of drought in the Middle East and southwest Asia. J. Climate, 29, 8547-8574, https://doi.org/10.1175/JCLI-D-13-00692.1.

Becker, E., and H. van den Dool, 2016: Probabilistic seasonal forecasts in the North American Multimodel Ensemble: A baseline skill assessment. J. Climate, 29, 3015-3026, https:// doi.org/10.1175/JCLI-D-14-00862.1.

Capotondi, A., and Coauthors, 2015: Understanding ENSO diversity. Bull. Amer. Meteor. Soc., 96, 921-938, https://doi.org/ 10.1175/BAMS-D-13-00117.1.

Chakraborty, A., S. K. Behera, M. Mujumdar, R. Ohba, and T. Yamagata, 2006: Diagnosis of tropospheric moisture over Saudi Arabia and influences of IOD and ENSO. Mon. Wea. Rev., 134, 598-617, https://doi.org/10.1175/MWR3085.1.

Cullen, H. M., and P. B. deMenocal, 2000: North Atlantic influence on Tigris-Euphrates streamflow. Int. J. Climatol., 20, 853-863, https://doi.org/10.1002/1097-0088(20000630)20:8<853:: AID-JOC497>3.0.CO;2-M.

_- A. Kaplan, P. A. Arkin, and P. B. deMenocal, 2002: Impact of the North Atlantic Oscillation on Middle Eastern climate and streamflow. Climatic Change, 55, 315-338, https://doi.org/ 10.1023/A:1020518305517.

Gall, C., 2008: War and drought threaten Afghan food supply. New York Times, 19 September, A1, https://www.nytimes.com/ 2008/09/19/world/asia/19afghan.html.

Gill, A. E., 1980: Some simple solutions for heat-induced tropical circulation. Quart. J. Roy. Meteor. Soc., 106, 447-462, https:// doi.org/10.1002/qj.49710644905.

Hoell, A., and C. Funk, 2013: The ENSO-related west Pacific sea surface temperature gradient. J. Climate, 26, 9545-9562, https://doi.org/10.1175/JCLI-D-12-00344.1.

— M. Barlow, and R. Saini, 2012: The leading pattern of intraseasonal and interannual Indian Ocean precipitation variability and its relationship with Asian circulation during the boreal cold season. J. Climate, 25, 7509-7526, https://doi.org/ 10.1175/JCLI-D-11-00572.1.

- , — , and —, 2013: Intraseasonal and seasonal-tointerannual Indian Ocean convection and hemispheric teleconnections. J. Climate, 26, 8850-8867, https://doi.org/10.1175/ JCLI-D-12-00306.1.

, C. Funk, and M. Barlow, 2014a: The regional forcing of Northern Hemisphere drought during recent warm tropical west Pacific Ocean La Niña events. Climate Dyn., 42, 32893311, https://doi.org/10.1007/s00382-013-1799-4.
,-- , and $-2014 \mathrm{~b}$ : La Niña diversity and northwest Indian Ocean rim teleconnections. Climate Dyn., 43, 2707-2724, https://doi.org/10.1007/s00382-014-2083-y.

$\ldots, \ldots$, and $\_, 2015 \mathrm{a}$ : The forcing of southwestern Asia teleconnections by low-frequency sea surface temperature variability during boreal winter. J. Climate, 28, 1511-1526, https://doi.org/10.1175/JCLI-D-14-00344.1.

, S. Shukla, M. Barlow, F. Cannon, C. Kelley, and C. Funk, 2015b: The forcing of monthly precipitation variability over southwest Asia during the boreal cold season. J. Climate, 28, 7038-7056, https://doi.org/10.1175/JCLI-D-14-00757.1.

- M. Barlow, F. Cannon, and T. Xu, 2017a: Oceanic origins of historical southwest Asia precipitation during the boreal cold season. J. Climate, 30, 2885-2903, https://doi.org/10.1175/ JCLI-D-16-0519.1.

_ C. Funk, M. Barlow, and F. Cannon, 2017b: A physical model for extreme drought over southwest Asia. Climate Extremes: Patterns and Mechanisms, Geophys. Monogr., Vol. 226, Amer. Geophys. Union, 283-298.

Hurrell, J. W., J. J. Hack, D. Shea, J. M. Caron, and J. Rosinski, 2008: A new sea surface temperature and sea ice boundary dataset for the Community Atmosphere Model. J. Climate, 21, 5145-5153, https://doi.org/10.1175/2008JCLI2292.1.

Johnson, N. C., 2013: How many ENSO flavors can we distinguish? J. Climate, 26, 4816-4827, https://doi.org/10.1175/ JCLI-D-12-00649.1.

Kao, H.-Y., and J.-Y. Yu, 2009: Contrasting eastern-Pacific and central-Pacific types of ENSO. J. Climate, 22, 615-632, https:// doi.org/10.1175/2008JCLI2309.1.

Krichak, S. O., P. Kishcha, and P. Alpert, 2002: Decadal trends of main Eurasian oscillations and the eastern Mediterranean precipitation. Theor. Appl. Climatol., 72, 209-220, https:// doi.org/10.1007/s007040200021.

Kug, J.-S., F.-F. Jin, and S.-I. An, 2009: Two types of El Niño events: Cold tongue El Niño and warm pool El Niño. J. Climate, 22, 1499-1515, https://doi.org/10.1175/2008JCLI2624.1.

Kumar, A., and M. P. Hoerling, 2000: Analysis of a conceptual model of seasonal climate variability and implications for seasonal prediction. Bull. Amer. Meteor. Soc., 81, 255-264, https://doi.org/ 10.1175/1520-0477(2000)081<0255:AOACMO > 2.3.CO;2.

_ and M. Chen, 2017: What is the variability in US west coast winter precipitation during strong El Niño events? Climate Dyn., 49, 2789-2802, https://doi.org/10.1007/s00382-016-3485-9.

Larkin, N. K., and D. E. Harrison, 2005: On the definition of El Niño and associated seasonal average U.S. weather anomalies. Geophys. Res. Lett., 32, L13705, https://doi.org/10.1029/ 2005 GL022738.

Madden, R. A., and P. R. Julian, 1972: Description of global-scale circulation cells in the tropics with a 40-50 day period. J. Atmos. Sci., 29, 1109-1123, https://doi.org/10.1175/1520-0469(1972)029<1109: DOGSCC $>2.0 . \mathrm{CO} ; 2$.

— cillation-A review. Mon. Wea. Rev., 122, 814-837, https://doi.org/ 10.1175/1520-0493(1994)122<0814:OOTDTO >2.0.CO;2.

Mann, M. E., 2002: Large-scale climate variability and connections with the Middle East in past centuries. Climatic Change, 55, 287-314, https://doi.org/10.1023/A:1020582910569.

Mariotti, A., 2007: How ENSO impacts precipitation in southwest central Asia. Geophys. Res. Lett., 34, L16706, https://doi.org/ 10.1029/2007GL030078.

Matsuno, T., 1966: Quasi-geostrophic motions in the equatorial area. J. Meteor. Soc. Japan, 44, 25-43, https://doi.org/10.2151/ jmsj1965.44.1_25. 
Nazemosadat, M. J., and A. R. Ghasemi, 2004: Quantifying the ENSO-related shifts in the intensity and probability of drought and wet periods in Iran. J. Climate, 17, 4005-4018, https://doi.org/ 10.1175/1520-0442(2004)017<4005:QTESIT>2.0.CO;2.

— Madden-Julian oscillation and precipitation variability in southern Iran and the Arabian Peninsula: Atmospheric circulation analysis. J. Climate, 23, 887-904, https://doi.org/ 10.1175/2009JCLI2141.1.

Niranjan Kumar, K., T. B. M. J. Ouarda, S. Sandeep, and R. S. Ajayamohan, 2016: Wintertime precipitation variability over the Arabian Peninsula and its relationship with ENSO in the CAM4 simulations. Climate Dyn., 47, 2443-2454, https:// doi.org/10.1007/s00382-016-2973-2.

Ramankutty, N., A. T. Evan, C. Monfreda, and J. A. Foley, 2008: Farming the planet: 1. Geographic distribution of global agricultural lands in the year 2000. Global Biogeochem. Cycles, 22, GB1003, https://doi.org/10.1029/2007GB002952.

Rasmusson, E. M., and T. H. Carpenter, 1982: Variations in tropical sea surface temperature and surface wind fields associated with the Southern Oscillation/El Niño. Mon. Wea. Rev., 110, 354-384, https://doi.org/10.1175/1520-0493(1982)110<0354: VITSST $>2.0 . \mathrm{CO} ; 2$.

Ryan, J., R. Sommer, and H. Ibrikci, 2012: Fertilizer best management practices: A perspective from the dryland west Asia-North Africa region. J. Agron. Crop Sci., 198, 57-67, https://doi.org/10.1111/j.1439-037X.2011.00488.x.
Saha, S., and Coauthors, 2014: The NCEP Climate Forecast System version 2. J. Climate, 27, 2185-2208, https://doi.org/10.1175/ JCLI-D-12-00823.1.

Saji, N. H., B. N. Goswami, P. N. Vinayachandran, and T. Yamagata, 1999: A dipole mode in the tropical Indian Ocean. Nature, 401, 360-363, https://doi.org/10.1038/ 43854.

Sardeshmukh, P. D., G. P. Compo, and C. Penland, 2000: Changes of probability associated with El Niño. J. Climate, 13, 42684286, https://doi.org/10.1175/1520-0442(2000)013<4268: COPAWE $>2.0 . \mathrm{CO} ; 2$.

Shaman, J., and E. Tziperman, 2005: The effect of ENSO on Tibetan Plateau snow depth: A stationary wave teleconnection mechanism and implications for the south Asian monsoons. J. Climate, 18, 2067-2079, https://doi.org/10.1175/ JCLI3391.1.

Syed, F. S., F. Giorgi, J. S. Pal, and M. P. King, 2006: Effect of remote forcings on the winter precipitation of central southwest Asia part 1: Observations. Theor. Appl. Climatol., 86, 147-160, https://doi.org/10.1007/s00704-005-0217-1.

Wyrtki, K., 1975: El Niño-The dynamic response of the equatorial Pacific Ocean to atmospheric forcing. J. Phys. Oceanogr., 5, 572-584, https://doi.org/10.1175/1520-0485(1975)005<0572: ENTDRO $>2.0 . \mathrm{CO} ; 2$.

Yeh, S.-W., J.-S. Kug, B. Dewitte, M.-H. Kwon, B. P. Kirtman, and F.-F. Jin, 2009: El Niño in a changing climate. Nature, $\mathbf{4 6 1}$, 511-514, https://doi.org/10.1038/nature08316. 